\title{
Polymeric Hollow Fibers: State of the Art Review of Their Preparation, Characterization and Applications in Different Research Areas
}

\author{
K.C. Khulbe ${ }^{1^{*}}$ C. Feng $^{2}$, T. Matsuura ${ }^{3}$ \& M. Khayet ${ }^{4}$ \\ ${ }^{1,2 \& \overline{3}}$ Department of Chemical Engineering, University of Ottawa, Ottawa, Ont. K1N 6N5, Canada \\ ${ }^{4}$ Department of Applied Physics I, Faculty of Physics, University Complutense of Madrid, Av. Complutense s/n, \\ 28040, Madrid, SPAIN
}

\begin{abstract}
In this article an attempt is made to review critically the papers published recently on polymeric hollow fibers and hollow fiber membranes. Hollow fiber membranes emerged in early nineteen sixties at almost the same time as the announcement of the cellulose acetate reverse osmosis membrane for seawater desalination by Loeb and Sourirajan. Since then, the hollow fiber technology has progressed along with the industrial membrane separation processes. Today, hollow fiber membranes are being used in every sector of the manufacturing industry, including gas and vapor separation, seawater desalination and waste water treatment. The fabrication of a hollow fiber membrane with a desirable pore-size distribution and performance is not an easy task. There are many factors controlling fiber morphology during the phase inversion process and, at present, we are not able to say that we fully understand the phenomena involved in the fabrication of hollow fibers. Nevertheless, there has been a large amount of knowledge accumulated during the past fifteen years, which has been supported by an equally large amount of efforts by many researchers. This paper attempts to summarize those works. The authors could however look into only those reports which have appeared in scientific journals and few patents, and they are fully aware that there must be much more information that has not surfaced to the journal publication. It is also the authors' intention to show the future direction including the research topics that have been studied only little or not at all.
\end{abstract}

Keywords: Polymeric hollow fibers, polymers, uses of hollow fibers, preparation of hollow fibers, filtration, membranes

\subsection{INTRODUCTION}

Applications of hollow fibers in membrane separation processes began when Mahon et al. in Dupont $[1,2]$ patented the permselective hollow fibers and the method of preparation in late 1960. Dupont later developed the hollow fiber module (Permasep) made of polyethylene terephthalate (PET) for the recovery of light gases [3, 4]. Another well known application of the hollow fiber in gas separation is polysulfone Prism Separator developed by Monsanto [5]. This is also known as a method to seal the defects at the selective dense layer by silicone rubber coating. As for the application of hollow

\footnotetext{
"Correspondence to: K.C. Khulbe (email: khulbe@eng.uottawa.ca.)
} 
fibers in reverse osmosis, Dupont's aromatic polyamide B9 module was introduced in 1969 for the first time for seawater desalination [6]. A number of these modules have been installed in the Middle East since then. Fabrication of hollow fibers from polysulfone (PSf) for ultrafiltration seems another important event. Cabbaso et al. proposed the addition of polyvinylpyrrolidone (PVP) to the casting dope. Since then, this has become a routine fabrication method of PSf UF hollow fibers [7]. Even though a large number of improvements have been made, it might be fair to say that the basic principle of the hollow fibers and hollow fiber modules was established by the above mentioned ew works.

Membrane technology at present time is extensively applied in many sectors of the manufacturing industry including gas and vapor separation, seawater desalination, waste water treatment and production of foods, beverages, pharmaceuticals and other biological products. Hollow fiber membranes are popularly used in all the above applications due to several advantages over conventional flat sheet membranes, but the most important one is its high area/volume ratio, as shown by the following figures;

Plate and frame: $100-400 \mathrm{~m}^{2} / \mathrm{m}^{3}$

Tubular: $300 \mathrm{~m}^{2} / \mathrm{m}^{3}$

Spiral wound: $300-1000 \mathrm{~m}^{2} / \mathrm{m}^{3}$

Hollow fiber: up to $30,000 \mathrm{~m}^{2} / \mathrm{m}^{3}$

The extremely large area to volume ratio of hollow fibers allows compactness of hollow fiber modules.

In general, hollow fibers are prepared by using the diffusion induced phase separation technique (DIPS) [8]. In this process, a solution of polymer and a solvent is contacted with a non-solvent for the polymer. This is also called the dry-wet phase inversion process. Due to initial inter-diffusion of solvent and non-solvent, the concentration of polymer solution changes and, finally phase separation occurs. Using this technique it is possible to produce asymmetric membranes with a graded pore size over the wall thickness, as well as completely symmetric membranes or even membranes wh closed or an open skin [9].

An alternative technique for producing porous structure is thermally induced phase separation (TIPS) [10]. In this process, polymer is dissolved in a poor solvent at a high temperature. On cooling the homogeneous solutions, phase separation sets in, resulting in a porous material after removal (generally via extraction) of the solvent. This process is applied for semi-crystalline polymers such as polyethylene, polypropylene and polytetrafluoroethylene, for which good solvents are difficult to find.

The fabrication of a hollow fiber membrane with a desirable pore-size distribution and performance is not an easy task. There are many factors controlling fiber morphology during the phase inversion. In hollow fiber spinning, the pressurized viscous solution will be subjected to various stresses when it extrudes through the complicated channel within a spinneret. These stresses may influence molecular orientation and relaxation, and subsequently fiber formation and separation performance, as well as fiber productivity [11]. Polymer macromolecules swell and relax when exiting from spinneret. If there is an air-gap before coagulation, there will be several other changes. As soon as the casting solution comes out from the spinneret, the stress perpendicular to the fiber axis will be released. The release of the stress perpendicular to the axis will result in the expansion of the fiber diameter. On the other hand, the stress parallel to the axis will elongate the fiber and decrease the fiber diameter. Beside this, the relaxation of polymer occurs, when polymer solution comes out of the spinneret, and continues until the hollow fiber travels a certain distance of air gap. During relaxation, the macromolecules tend to coil with each other, enhancing the fusion of the nodule/nodule aggregate. The effect of air-gap on the performance of the hollow fiber and on its morphology is therefore quite complex. It depends on the property of polymer, method of fabrication, spinning temperature, properties of bore fluid, air-gap, chemistry of coagulant bath and its compositions. Thus, a smal change in the membrane formation parameters can change the membrane morphology and consequently have a drastic effect on the performance of membrane. Furthermore, the mechanism for asymmetric hollow fiber formation is much more complicated than that for asymmetric flat membranes. It is easily understandable by considering that the demixing takes place both from the bore side and from the outside.

Despite this complexity, significant advances have been made in both membrane materials and fabrication technology during the last 15 years. This review attempts to summarize the recent advances in the hollow fiber science and technology. Gerlach and Kessler [12] patented a method for the preparation of porous fibers. Their patent concerns porous fibers and membranes, methods for their preparation and for their use. The fibers were characterized by a smooth porous surface and an apparent density of between about 10 and $90 \%$ of the true density of the polymeric starting material apparent density of between about 10 and $90 \%$ of the true density of the polymeric starting materia
employed. The process involved the formation of a homogeneous mixture of at least two components, employed. The process involved the formation of a homogeneous mixture of at least two components,
one of which is a meltable polymer and another liquid inert with respect to the polymer. The mixture one of which is a meltable polymer and another liquid inert with respect to the polymer. The mixture
formed must be of a binary type, in which there is a temperature range of complete miscibility and a range in which there is a miscibility gap. The mixture is extruded at a temperature above the separation temperature into a bath containing at least some of the inert liquid which is at a temperature below the separation temperature. Upon introduction of the mixture into the bath, the fiber structure of the product (hollow fiber) is fixed.

\subsection{PREPARATION, CHARACTERIZATION AND PERFORMANCE IN VARIOUS APPLICATIONS}

\subsection{Gas Separation}

Mckelvey et al. [13] summarized the effects of parameters on the macroscopic dimension of membranes as a general guideline of dry-jet wet hollow fiber spinning

\subsection{Polysulfone (PSf)}

Kesting et al [14] in the study of PSf hollow fiber membrane for gas separation observed that macrovoids in the hollow fiber membranes play a part in intrinsic selectivity of the gases. Macrovoid concentration decreases with increase of polymer concentration and viscosity.

Fritzsche et al. [15] studied the structures of PSf hollow fiber membranes, spun from the propionic acid (PA)/N-methylpyrrolidone (NMP) complex and from a formylpiperidine (FP)/formamide (FA) mixture as a function of progressive surface removal with oxygen plasma. It was observed that the hollow fiber membrane spun from the PA: NMP complex had both a thinner active separating layer and a thinner skin than the PSf hollow fiber membrane spun from the FP:FA mixture. The substrate of the PA:NMP complex spun hollow fiber membrane had greater porosity and less tortuosity than its FP/FA congener. The oxygen plasma ablation results and the SEMs demonstrate a non-equivalence between the active separating layer and the microscopically observable skin of the hollow fiber membranes. It was concluded that membranes prepared from Lewis acid:base complex (PA:NMP) solvents possess a porous substructure and a non-uniform (graded density) skin which consists of a very thin active separating layer whose effective thickness varies depending upon the gases to be separated and a thin less dense transition layer which may contain pores whose sizes are below the limits of resolution by SEM. 
According to Fritzsche et al. [16], PSf hollow fiber membranes with increased free volumes as reflected by elevated glass transition temperatures can be obtained from a spectrum of Lewis acid:N methylpyrrolidone (NMP) complexes. Oxygen plasma ablation experiments have shown that the active separation layer of these membranes decreases in the order formic acid:NMP $>$ acetic acid:NMP > propionic acid:NMP > butyric acid:NMP > isobutyric acid:NMP.

Fritzsche et al. [17] studied the structure of the effective separating layer of an asymmetric PSf hollow fiber membrane with a graded density skin by SEM, TEM and the osmium tetroxide adsorption and compared to that of a bilayer asymmetric hollow fiber membrane prepared from a solvent/nonsolvent mixture. The study revealed the presence of micropores which transverse the effective separating layer of the membrane with graded density skin. It was concluded that the enhanced free volume in an asymmetric hollow fiber membrane with a graded density skin exists in the effective separating layer as well as in the membrane interior.

Ismail et al. prepared super-selective PSf hollow fiber membranes for gas separation using a drywet spinning process with forced convection in the dry gap. Authors reported that a forced-convection spinning process, the combination of a high extrusion rate (shear rate) and a reduced water activity in the bore produced highly selective membranes. Further, they proposed that, if special skin formation conditions prevailed, increased shear could create an oriented and highly ordered membrane active layer which could exhibit selectivities significantly greater than the recognised intrinsic value for the isotropic polymer. Further, they noticed that lowering the bore fluid coagulation strength was necessary to preserve a highly engineered super-selective active layer [18]

Ismail et al. [19] investigated the influence of dope extrusion on morphology and gas separation performance of asymmetric PSf hollow fiber membranes. The asymmetric PSf hollow fiber membranes subjected to gas separation were prepared from a mixture of PSf, DMAc, tetrahydrofuran and ethanol. Fibers were spun at various dope extrusion rates (DER) ranging from $1.5-3.0 \mathrm{~cm}^{3} \mathrm{~min}^{-1}$ and hence at different levels of shear. The results indicated that on increasing the dope extrusion rate, the selectivity was increased until a critical level of shear was reached, beyond which the membrane performance deteriorated.

A super-selective PSf hollow fiber membrane for gas separation was demonstrated by Gordeyev et al. [20]. They also reported the rheological assessment of the spinning solution.

Bhardwaj et al. [21] incorporated three different fillers, carbon black (CB), vapor grown carbon fibers (VGCF) and $\mathrm{TiO}_{2}$ into PSf spinning solution for the preparation of hollow fibers with the intention of producing highly selective membranes with enhanced mechanical strength. For all filler types (at a concentration of $5 \% \mathrm{ww}$ ), the pressure-normalized flux of $\mathrm{O}_{2}, \mathrm{~N}_{2}$ and $\mathrm{CH}_{4}$ were greater in the composite than in the unfilled membranes. The $\mathrm{CO}_{2}$ pressure-normalized flux was only greater in the $\mathrm{TiO}_{2}$ composite membranes. All the filled membrane types exhibited greater mechanical strength $\mathrm{Su}$ (bursting pressure) than unfilled fibers apart from the $5 \% \mathrm{w} / \mathrm{w}$ VGCF composites. The $2 \% \mathrm{w} / \mathrm{w}$ $\mathrm{CB}$ composites were the strongest. Electron microscopy showed no visible differences in general morphology between the various filled and unfilled membranes.

Wang et al. [22] fabricated high-flux PSf hollow fiber membranes for gas separation by using $\mathrm{NMP} / \mathrm{H}_{2} \mathrm{O}$ and NMP/ethanol solvent systems. While water was external coagulant, the internal coagulants were water, ethanol, 2-propanol, the mixture of water/ethanol and water/2-propanol. The effects of air-gap, polymer concentration and coagulation bath temperature on the membrane structure and gas permeation properties were investigated. The air gap had significant effect on the hollow fiber separation performance. Proper selection of internal coagulant such as the mixture of water and $\mathrm{C}_{1}-\mathrm{C}_{3}$ aliphatic alcohols was an efficient method to alter membrane structure with the maintenance of good permeability and selectivity. It was also observed that NSA (nonsolventadditives) played an important role in controlling membrane structure and separation performance.

Wang et al. [23] prepared high-flux PSf hollow fiber membranes from $\mathrm{NMP} / \mathrm{H}_{2} \mathrm{O}$ and NMP/ ethanol solvent systems. Water was used as the external coagulant. The membranes were characterized by measuring their gas permeation properties for $\mathrm{He}, \mathrm{CO}_{2}, \mathrm{O}_{2}$ and $\mathrm{N}_{2}$ and by examining crosssectional structures using SEM. A dilute silicone coating method was used to seal defects on the outer surface of the hollow fiber. The silicone-coated hollow fibers exhibited $\mathrm{O}_{2}$ permeance of 20-30 GPU and $\mathrm{O}_{2} / \mathrm{N}_{2}$ selectivity of $5-6.5$ at $25^{\circ} \mathrm{C}$

Clausi and Koros [24] developed a rapid feedback characterization technique for PSf hollow fiber membranes for gas separation using disperse dyes. This technique involves dyeing wet hollow fibers, immediately after spinning, in an aqueous dye bath. Dye uptake in the hollow fibers is a function of skin porosity, thereby allowing quick evaluation of permeation characteristics. Dye uptake can be measured by using UV-visible spectrophotometer.

Horváth et al. [25] used PSf-PI hollow fiber for membrane gas separation to recover bio-hydrogen produced by Thiocapsa roseopersicina.

Qin et al. [26] demonstrated for the first time a continuous coating technique for fabrication of PSf/PVP/silicon rubber multi-layer composite hollow fibers for $\mathrm{CO}_{2} / \mathrm{CH}_{4}$ separation. A hypothesis that a water swollen PVP thin layer enhanced permeance of $\mathrm{CO}_{2}$ was proposed.

\subsection{Polyethersulfone (PES)}

Wang et al. [27] introduced highly permeable polyethersulfone (PES) asymmetric hollow fiber membranes which were prepared by using water as non-solvent (NSA) additive. The effects of various spinning conditions including polymer concentration, length of air gap, non-solvent strength of the internal coagulant and post treatment on the permeation properties and structures of the resulting hollow fibers were investigated. The viscosity of the spinning solutions was dramatically increased in the presence of water as an NSA. Ultra-thin skinned PES asymmetric hollow fibers with apparent skin layer thickness around 420-600 $\AA$ as determined by gas permeation flux were prepared under suitable spinning conditions. After silicone coating to repair surface defects, these hollow fibers exhibited gas selectivity higher than that of the PES dense film. The use of an internal coagulant with a moderate non-solvent strength had been shown to improve hollow fiber integrity and suppress macrovoid formation.

\subsection{Polyimide (PI)}

Wallace et al. [28] wrote an article on the efficient development of effective hollow fiber membranes for gas separation from novel polymers. In this article they discussed on high volume gas separation application of asymmetric hollow fibers and described also an approach for the development of firstapplication of asymmetric hollow fibers and described also an approach for the development of first-
generation asymmetric hollow fiber for gas separation membrane using small amounts of novel experimental polymers. They also discussed how to get high-speed fiber spinning from the help of polymer properties. A case study using cross-linkable PI was discussed to illustrate.

Chung and Kafchinski [29] studied the effects of inner and external coagulants, gelation bath temperature, and air-gap distance on the morphology and performance of the asymmetric 6FDA/ 6FDAM polyimide (PI) hollow fiber membranes subjected for air-separation. An increase in air-gap distance led to the formation of three-dimensional open-cell pore. Similar behaviour was also observed on raising the bath temperature. On choosing bore-fluid flow rate and gelation bath temperature properly, the multilayer finger void structure could be eliminated completely. Experimental data demonstrated that the location of the dense layer could be shifted from the inner skin to the outer skin based on the chemistry (solubility parameter) of coagulations. A defect free 6FDA/6FDAM polyimide fiber with a selectivity of 4.73 and a permeance of 38.1 GPU was produced.

Lin and Chung [30] investigated the aging phenomenon of asymmetric 6FDA-durene PI hollow fibers spun with different shear rates for gas separation. The permeances and selectivities of different 
gases namely $\mathrm{He}, \mathrm{O}_{2}, \mathrm{~N}_{2}, \mathrm{CH}_{4}$ and $\mathrm{CO}_{2}$ were experimentally determined as a function of time for around five months at room temperature. It was noticed that the gas permeation fluxes of the uncoated and silicon rubber coated hollow fibers decreased significantly during the first thirty days following fabrication and then slightly deteriorated thereafter. The permeance of 6FDA-durene hollow fibers coated with silicone rubber dropped more significantly than the uncoated fibers, implying that silicon rubber coating did affect the aging behavior. The explanation of this behavior was that silicon rubber hindered the molecular relaxation and tightened interface molecules between the dense selective layer and silicone rubber, thus the selectivity increased with aging. Thermal analysis suggested that there were two processes occurring simultaneously during the aging; (a) the relaxation of shear oriented chains, and (b) the densification of chain packing through the reduction of interstitial space among chains.

Carruthers et al. [31] prepared via a dry-jet, wet-quench process with a spinning solution composed of Matrimid ${ }^{\circledast}$ PI and components of varying volatility. It was observed that all the membranes were defect-free. SEM images revealed a prominent dense skin layer across the fiber's entire outer circumference. Skin-thickness estimates from thirty six SEM images and $\mathrm{N}_{2}, \mathrm{O}_{2}$ and He pure gaspermeation measurements agreed to within 9,7 , and $24 \%$ for defect-free membranes with 150,300 , and $600 \mathrm{~nm}$ skin thickness, respectively.

Kazama and Sakashita [32] studied hollow fiber membranes for gas separation, prepared from a cardo PI by using a wet phase inversion process. Polymer dope contained a mixture of cardo PI, LiCl and NMP, and water was used as an inner and outer coagulant. The membrane was stable up to $240^{\circ} \mathrm{C}$. It was observed that the cardo PI hollow fiber membrane had a skin layer in the inside surface, whereas the outside surface was porous. The inner skin layer was constructed from nodular substances, and classified into three parts, that is, a topmost layer, an underlying transition region, and a porous substrate, because of the difference in morphology. The topmost layer consisted of rounded cylindrical nodules elongated along spinning flow, whose average dimensions were about $6.5 \mathrm{~nm}$ in diameter and around $15 \mathrm{~nm}$ in length. The orientation of nodules along spinning flow was observed. The nodules were layered in double to form the dense, defect free topmost layer, of which the thickness was about $11 \mathrm{~nm}$ on average. In the underlying transition region, even though the nodule diameter was similar, they observed many micro voids, and its thickness was about $80 \mathrm{~nm}$. And, in the porous substrate, nodules became larger as receding from the surface. On the other hand, the outer surface of the hollow fiber membrane was porous. From the gas permeation data, defect-free skin thickness was estimated to be about $100 \mathrm{~nm}$. This indicates that the topmost layer together with the underlying transition layer forms a skin layer for gas permeation, even though micro-voids exist in the underlying transition region in TEM observation.

Barsema et al. [33] characterised the highly selective dense flat sheet and hollow fiber asymmetric membranes based on BTDA-TDI/MDI co-polyimide. This copolyimide was a commercial polymer produced by Lenzing with the trade name P28. Dry/wet phase inversion process was used for the preparation of fibers. It was noted that the ideal selectivity $\left(\mathrm{He}, \mathrm{CO}_{2}, \mathrm{O}_{2}\right.$ and $\left.\mathrm{N}_{2}\right)$ of asymmetric hollow fibers were comparable with those measured for dense membranes but the plasticization behaviour was quite different. $\mathrm{P} 84$ asymmetric hollow fibers showed severe plasticization effects, starting immediately at low pure $\mathrm{CO}_{2}$ feed pressure. However, plasticization phenomena was suppressed when a gaseous mixture consisting $\mathrm{CO}_{2} / \mathrm{N}_{2}(80 / 20)$ was used instead of pure $\mathrm{CO}_{2}$

It is well known that physical aging of the selective skin results in significant age-dependent permeation properties in thin films and asymmetric membranes. Madden et al. [34] studied the physical aging effect on the Matrimid® hollow fiber membranes subjected to gas separation. Table shows the effect of physical aging on the permeation properties of low-sorbing gases in Matrimid $^{\circledR}$ The reduction in permeances and the increase in selectivities shown in Table 1 are due to the densification of the selective skin layer. It was also suggested that the porous substructure of an asymmetric hollow fiber may also undergo accelerated physical aging.
Table 1 Effect of physical aging on the permeation properties of low-sorbing gases in Matrimid ${ }^{\circledR}$

\begin{tabular}{llllll}
\hline $\begin{array}{l}\text { Aging time } \\
\text { (days) }\end{array}$ & $\begin{array}{l}\mathbf{N}_{2} \text { permeance } \\
\text { (GPU) }\end{array}$ & $\begin{array}{l}\mathbf{O}_{2} \text { permeance } \\
\text { (GPU) }\end{array}$ & $\begin{array}{l}\text { He permeance } \\
\text { (GPU) }\end{array}$ & $\begin{array}{l}\mathbf{O}_{2} / \mathbf{N}_{2} \\
\text { selectivity }\end{array}$ & $\begin{array}{l}\mathbf{N}_{2} / \mathrm{He} \\
\text { selectivity }\end{array}$ \\
\hline $2^{\mathrm{a}}$ & 0.93 & 6.49 & 82 & 6.97 & 88 \\
$254^{\mathrm{b}}$ & 0.62 & 4.18 & 63 & 6.74 & 101 \\
$407^{\mathrm{b}}$ & 0.39 & 2.88 & 45 & 7.38 & 115 \\
\hline
\end{tabular}

a Measurement taken at $27^{\circ} \mathrm{C}$

${ }^{b}$ Measurement taken at $35^{\circ} \mathrm{C}$

Transient permeation (time lag) is a popular method for studying gas diffusion and sorption in glassy polymers [35]. The permeation flux and time lag have been studied for polymer membranes of slab geometry. The time lag method is frequently seen in the research of gas permeation in polymeric hollow fibers [33, 36]. Yoshino et al. [36] investigated gas permeation properties of asymmetric hollow fibers $[33,36]$. Yoshino et al. [36] investigated gas permeation properties of asymmetric
hollow fiber membranes of copolymer prepared from equimolar portion of 2,2-bis (3,4dicarboxyphenyl) hexafluoropropane dianhydride (6FDA) and 3,3',4,4'-biphenyltetracarboxylic dianhydride (BPDA) with 3,7-diamino-2,8(6)-dimethyldibenzothiophene sulfone (DDBT) for singlecomponent light gases, olefins and paraffins and for mixed components of $\mathrm{C}_{3} \mathrm{H}_{6} / \mathrm{C}_{3} \mathrm{H}_{8}$ and $\mathrm{C}_{4} \mathrm{H}_{8} /$ $\mathrm{C}_{4} \mathrm{H}_{10}$. Gas permeance of the asymmetric copolyimide hollow fiber membrane decreased significantly in the first severa months and leved off after about 10 months of aging. Their study showed that in phenomentification of ich was caused by aging. The silicone rubber coating hardly changed the selectivity of light gas pairs such as $\mathrm{H}_{2} / \mathrm{CH}_{4}$ and $\mathrm{O}_{2} / \mathrm{N}_{2}$. On the other hand, the selectivity for $\mathrm{C}_{3} \mathrm{H}_{6} / \mathrm{C}_{3} \mathrm{H}_{8}$ and $\mathrm{C}_{4} \mathrm{H}_{8} / \mathrm{C}_{4} \mathrm{H}_{10}$ was enhanced significantly especially at low temperatures. The resistance model suggested that the extremely small surface porosity of defect pores, which hardly affects the separation performance for the light gas pairs, significantly spoils that for the larger gas pairs.

Koros and Woods [37] studied three asymmetric hollow-fiber polymer membrane systems for application in elevated temperature, low feed pressure systems: (i) a single component poyaramide, (ii) a single component polyimide, and (iii) a composite polyimide on a polyimide/polyetherimide blend support. Polyaramide membranes were shown to exhibit good stability at elevated temperatures $\left(23-220^{\circ} \mathrm{C}\right)$ and good separation properties after silicon rubber post-treatment. The PI membranes showed reasonable thermal stability below $150^{\circ} \mathrm{C}$, but underwent a rapid aging process at higher temperature. Aging reduced the permeability of the membranes by one-third and slightly increased perm-selectivity. However, as the aging effects leveled off, the PI membrane still exhibited approximately $400 \mathrm{GPU}$ oh hydrogen permeance with mixed gas selectivities of hydrogen over nitrogen and n-butane of 130 and 660 , respectively.

\subsection{Polyetherimide (PEI)}

Wang et al. [38] studied high gas selective PEI hollow fiber membranes which were prepared by introducing volatile organic compounds as additives into the dope solution. The additives were methanol, acetone and a mixture of methanol/acetone and tetrahydrofuran (THF) and the solvents were NMP and DMAc. Water was used as an external coagulant, while bore fluid was $50 \mathrm{wt} \%$ ethano in water. It was observed that parameters such as the solvent, additive and air gap affected the skin layer formation. Asymmetric PEI hollow fiber membranes with high selectivity could be obtained by using volatile non-solvent additives and NMP as the solvent at a suitable length of the air-gap. The PEI hollow fiber membrane prepared using THF as the additive showed poor selectivity. 
Wang et al. [39] studied the permeation properties of pure $\mathrm{H}_{2}, \mathrm{~N}_{2}, \mathrm{CH}_{4}$ and $\mathrm{C}_{3} \mathrm{H}_{8}$ through asymmetric PEI hollow-fiber membranes as a function of pressure and temperature. The PEI hollowfiber was spun from a NMP/ethanol solvent system via a dry-wet phase inversion method, with water as the external coagulant and $50 \mathrm{wt} \%$ ethanol in water as the internal coagulant. The prepare asymmetric membrane exhibited sufficiently high selectivity $\left(\mathrm{H}_{2} / \mathrm{N}_{2}\right.$ selectivity $>50$ at $\left.25^{\circ} \mathrm{C}\right)$. The permeability of $\mathrm{H}_{2}$ increased greatly with increasing temperature. Meanwhile, a slight permeability increment with increasing temperature was noted for $\mathrm{N}_{2}$ and $\mathrm{CH}_{4}$, whereas the permeability of $\mathrm{CH}_{4}$ and $\mathrm{C}_{3} \mathrm{H}_{8}$ decreased with increasing temperature.

Kapantaidakis et al. [40] reported that the longer the nascent hollow fiber polyethersulfone polyimide blend (PES-PI blend) is exposed to humid air-gap, the higher surface porosity and ga permeance. By increasing the velocity of the take-up drum, the permeance of both $\mathrm{CO}_{2}$ and $\mathrm{N}_{2}$ decreased while their permselectivity remained constant. Kapantaidakis and Koops [41] studied the formation and gas permeation properties of hollow fiber membranes based on PES/PI blends of three compositions (80/20,50/50 and 20/80 weight ratio). They reported that the air-gap affected both membrane structure and permeation properties in the dry-wet spinning process.

In another article, Kapantaidakis et al. [42] reported the preparation and characterization of PES-PI (polyimide Matrimid 5218) blend membranes. SEM was used to investigate the morphological characteristics and structure of the asymmetric hollow fibers. Differential scanning calorimetery (DSC) was used to determine the glass transition temperatures of the blends. The permeation rate of $\mathrm{CO}_{2}$ and $\mathrm{N}_{2}$, for both uncoated and PDMS coated fibers, were measured by the variable pressure method. They concluded that PES-PI hollow fibers as excellent candidate membranes for the separation of gaseous mixture in industrial level.

Khulbe et al. [43] characterized PES-PI hollow fiber membranes for gas separation prepared at different air-gap by AFM and by measuring the contact angle. AFM images revealed that the oute surface was entirely different than the inner surface. On the inner surface nodule aggregates were aligned in rows towards the direction of bore fluid flow. On the outer surface, alignment of nodula aggregates in one direction was not observed. The average mean roughness parameter of the inner surface increased with the increase in air-gap. On the other hand, opposite was the case for the oute surface. Gas permeation rate increased with the increase in air-gap. An attempt was made to find relationship between the surface morphology observed by AFM and permeability and selectivity of the studied hollow fiber membrane. From the contact angle measurement it was observed that the contact angle was directly related to the outside surface roughness.

Wang et al. [44] prepared integral asymmetric PEI hollow fiber membranes for gas separation using NMP as a solvent and ethanol as a non-solvent additive by using dry-wet phase inversion technique. Water was used as both an internal and external coagulant. The membrane structure and gas separation properties were examined. It was reported that the length of air-gap played an important role in the spinning process and greatly affected the membrane separation performance.

Qin and Chung [45] prepared PI composite hollow fiber membranes with PSf as substrates for gas separation. Five fluorinated polyimides (including 6FDA-durene, 6FDA-durene-mPDA, 6FDA pSED, 6FDA-mSED and 6FDA-ODA) coated on a PSf substrate were tested to demonstrate the potentiality of fabricating defect-free hollow fibers from fluorinated PI composite membranes.

\subsection{Polyvinylidene Fluoride (PVDF)}

Meng et al. [46] span microporous PVDF hollow fiber membrane by using the dry-wet phase inversion technique. A uniform coating with thickness of around 5-12 um of polydimethylsiloxane (PDMS) was deposited on the surface by using dip-coating technique. The structural parameters of PVDF substrate membrane was estimated by gas permeation test. The experimental data of both permeability
$\left(\mathrm{N}_{2} / \mathrm{O}_{2}\right)$ and selectivity were in good agreement with the theoretical results predicted by the presented pore-distribution model. It was suggested that the thickness of PDMS skin must be higher than $5 \mu \mathrm{m}$ to obtain compact composite membranes without defects.

Yeow et al. [47] investigated the characteristics of the spinning solutions following the addition of $\mathrm{LiClO}_{4}$ based on solution viscosity measurement and the PVDF/DMAc/LiClO 4 /water quaternary system phase diagram. A significant increase in solution viscosity was found following the increase in the amount of $\mathrm{LiClO}_{4}$ used. The shift of bimodal-curve for the isothermal phase diagram clearly demonstrated a significant reduction in the system tolerance for non-solvent following the addition of $\mathrm{LiClO}_{4}$ contents. The data obtained from gas permeation revealed an increase in the pore size coupled with a more uniform pore size distribution as the amount of $\mathrm{LiClO}_{4}$ added was increased from 1 to $3 \mathrm{wt} \%$. An increase in coagulation bath temperature was found to be advantageous in the production of a network membrane pore structure with higher permeation performance with aid of a sufficient amount of additive. However, excessive additive would have the adverse effect.

\subsection{Polyphenylene Oxide (PPO)}

Hollow fibers were spun from the solution of poly (2,6-dimethyl-1,4-phenylene oxide)(PPO) in cyclohexanol by TIPS. The phase separation took place upon cooling. Dry spinning (temperature as a parameter) and air-gap spinning (length of air gap as a parameter) were attempted. The fibers were used for the separation of oxygen and nitrogen. Although the hollow fibers exhibited perfect separation, the flux was too low. Cooling rate was correlated to the skin layer thickness. Moreover, a mathematical model was presented to calculate the cooling rate [10]

Berghmans et al. [49] fabricated hollow porous fibers by spinning a solution of poly (2,6 dimethyl1,4-phenylene ether) (PPE)/cyclohexanol by TIPS technique. Liquid-liquid phase separation of this system is around $100^{\circ} \mathrm{C}[48,49]$. Fibers were spun under these de-mixing conditions. Depending on the cooling rate applied, two different solidification mechanisms could be possible. At low cooling rates, PPE crystallized while at high cooling rates liquid-liquid phase separation, followed by vitrification, could be realized. Only the latter mechanism is of interest for the preparation of hollow fibers. Both spinning techniques, i.e. dry spinning and dry-wet spinning, were used at high cooling rate. It was reported that when thermal phase separation occurred (dry-wet), membranes with closed skin could be obtained. On the other hand, on dry-spinning, a thin skin was obtained on the outside of the fiber formed by evaporation of the solvent. A highly asymmetric porous structure membrane was obtained by air-gap method. The fibers were used for the separation of oxygen and nitrogen and the observed selectivity was perfect, however permeability was too low.

\section{$2.8 \quad$ PV and VP}

\subsection{PV-deydration}

Tsai et al. [49] fabricated PSf hollow fiber membranes for pervaporation by using dry/wet spinning technique, with $N$-methylpyrrolidinone (NMP) and water as solvent and coagulant, respectively. The results indicated that air-gap length and ambient humidity had dramatic effect on the membrane morphology. Macro-voids in the membranes disappeared, reappeared, and redisappeared with
morat increasing air-gap length

It might be due to the high affinity of NMP for water. Water vapor was drawn to the dope to induce phase separation, resulting in a nascent structure in the dope before it was immered in the the dope behaved as a transient gel, which could reasonably explain the disappearance and 
redisappearance of macro-voids. It was also noticed that the air-gap length required for the disappearance and reappearance of macro-voids decreased with increasing ambient humidity, which could be well reasoned by the decreasing contact time with the humid air needed to bring about phase separation of the dope in the air gap.

Tsai et al. [50] investigated the influence of heat treatment conditions on the morphology and pevaporation performances of aqueous isopropanol (IPA) solution through wet spinning prepared polyacrylonitile (PAN) hollow fiber membranes. The membranes were also characterised by SEM and AFM. At heat-treatment temperature higher than $210^{\circ} \mathrm{C}$, dehydrogenation and cyclization reaction of the PAN molecules occurred during heat treatment. The SEM observation depicted that the morphology of heat-treated PAN hollow fiber membranes became denser with increasing heattreatment temperature. Compared with the precursor hollow fiber membrane, the pervaporation performances of heat-treated PAN hollow fiber membranes significantly improved.

Shen et al. [51] investigated the separation of water/isopropanol mixtures by pervaporation through carboxymethyl chitosan (CMCS)/polysulfone (PSf) hollow-fiber composite membranes prepared with glutaraldehyde as crosslinking agent. The effects of feed composition, crosslinking agent, membrane thickness, and feed temperature on membrane performance were investigated. The results showed that the crosslinked CMCS/PSf hollow fiber composite membranes possess high selectivity and promising permeability.

\subsection{PV-VOCs Removal from Water}

Wu et al. [52] investigated PVDF asymmetric hollow fiber membranes prepared by a phase inversion method using DMAc and a mixture of Water/ $\mathrm{LiCl}$ as solvent and a nonsolvent additive, respectively. Membranes were characterised by SEM for observing its microstructures and by a gas permeation method for measuring its surface porosity, pore size, and pore size distribution. A membrane module was fabricated to remove benzene/toluene from water by using vacuum membrane distillation technique. The benzene/toluene removal was achieved over $99 \%$ under an optimal operating condition. Mass transfer of benzene or toluene removal was controlled not only by the liquid phase resistance but also by the membrane and gas phase resistances. Benzene and toluene could be removed from water simultaneously with no adverse coupling effects.

Wu et al. [53] prepared PVDF hollow fiber membranes with an asymmetric structure by the phase inversion technique using DMAc as a solvent. $\mathrm{LiCl}-\mathrm{H}_{2} \mathrm{O}$ was used as an additive. These membranes were applied for volatile organic compounds (VOCs) removal from water (vacuum distillation operation). The effects of various operating parameters including downstream vacuum level, feed temperature, feed flow rate and TCA (1,1,1-trichloroethane) feed concentration on the performance of the module were investigated both theoretically and experimentally. Under the optimal experimental conditions, up to 97\% TCA was removed. A mathematical model, without any adjustable parameters was developed based on the mass transfer resistances in both liquid and membrane phase. All the parameters used in the mathematic model were determined from either membrane characteristics or independent relationships. The theoretical predictions from the mathematical model were generally consistent with the experimentally measured values over moderate pressure and temperature ranges.

Keller and Bierwagen [54] demostrated that hydrophobic hollow fiber membranes could be used for treating MTBE (methyl tert-butyl ether) contaminated water by pervaporation. By increasing the solution's temperature the Henry's constant as well as overall mass transfer coefficient could be increased.

Yamaguchi et al. [55] prepared hollow-fiber-type pore filling membranes subjected to pervaporation by using plasma-graft polymerization technique for the removal of chlorinated organics from water.
Laurylacrylate (LA) or n-butylacrylate (BA) grafted layers were formed inside the pores. They demonstrated that pore-filling membrane could easily remove organics from water because of the suppression of the membrane swelling by the porous substrate matrix, and the fact that it can maintain a high solute diffusivity, because of the linear graft chains that fill the substrate pores.

\subsection{Vaper Permeation}

Chung et al. [56] used commercial asymmetric polyimide hollow fiber membrane (UBE Industry, Ltd. Japan) for the separation of chlorofluorocarbons ( $\mathrm{CFCs}$ ) from air. The polyimide hollow-fiber Lid. Japan had the membrane had a thin outer dense layer supported by a microporous structure. It wane had a promising potential for the separation of CFC-12 (dichloropolyimide membrane had a promising potential for the separation of CFC-12 (dichloro-
difluoromethane) from CFC-12/air mixture. Mathematical models were derived, and the performance difluoromethane) from CFC-12/air mixture. Mathematical models were derived, and the perforn
of the membrane was well correlated with the one predicted by the mathematical model.

Yeow et al. [57] used divinyl-polydimethylsiloxane (divinyl-PDMS)/PVDF composite hollow fiber membrane for the removal of benzene, toluene and xylene (BTX) from hydrocarbon/nitrogen mixture at a temperature of $40^{\circ} \mathrm{C}$. They claimed the recovery was greater than $95 \%$.

Zhen et al. [58] developed polydimethylsiloxane-PVDF (PDMS-PVDF) composite membranes and applied for separation of a wide variety of volatile organic compounds (benzene, chloroform, acetone, ethyl acetate and toluene). The results showed that the composite PDMS-PVDF hollow fiber membranes exhibited very high removal efficiency $(>96 \%)$ for all the VOCs under favourable operating conditions.

Mujumdar et al. [59] attempted removal of VOCs from nitrogen via vapor permeation using micro ayer by both laboratory scale and pilot plant experiments. Results from two pilot scale experiments with an emission from a reactor in a pharmaceutical plant and an air emission from a paint booth is reported.

\subsection{Membrane Contactor}

Bhaumic et al. [60] attempted removal of advanced oxidation byproducts such as $\mathrm{CO}_{2}, \mathrm{O}_{2}$ etc. from water with a porous hydrophobic polypropylene hollow fiber module with an ultrathin coating of perfluorodimethyldioxole-tetrafluoroethylene.

Kosaraju et al. [61] carried out continuous $\mathrm{CO}_{2}$ absorption-stripping for 55 days using polyamide amine dendrimer as an absorbent in an aqueous solution using polypropylene hollow fiber in an a to eliminate the pore weting and loss of volatile nonoethanolamine from aqueous solution by using absorber and stripper made of poly(4-methyl-1-pentene) hollow fibers having an ultrathin dense skin.

Wang et al. [62] discussed the utilization of polypropylene (PP) hollow fiber membranes in a contactor for the removal of gaseous ammonia directly from the gas mixture produced in the ammonia manufacturing process. This is to find an economic way to substitute conventional soft-water washing absorption technology.

Li [63] investigated the tailor-made asymmetric PVDF hollow fiber membranes for soluble gas $\left(\mathrm{H}_{2} \mathrm{~S}\right.$ or $\left.\mathrm{SO}_{2}\right)$ removal from waste gas stream. The membranes with different morphological structures have been prepared using phase-inversion process and characterised by SEM. This study was focused on techniques of fabricating and characterizing the PVDF asymmetric hollow fiber membranes used as a stable interface for absorption of $\mathrm{H}_{2} \mathrm{~S}$ or $\mathrm{SO}_{2}$ using an alkaline solution. Experimental result obtained from the different membranes developed indicate that the PVDF membrane with much 
reduced membrane resistance could be prepared by properly selecting the internal coagulant and adding an appropriate additive in its polymer forming solution.

Tan et al. [64] prepared PVDF hollow fiber membranes with an asymmetric structure and good hydrophobicity by using the phase-inversion method, subjected to removal of ammonia from water A mathematical model was presented to simulate the ammonia removal in PVDF hollow fiber modules. Experimental results indicated that the post treatment with ethanol was useful to improve both the hydrophobicity and the effective surface porosity of the resulting PVDF hollow fiber membranes. All the experimental data were in excellent agreement with the modeling results.

\section{$3.0 \mathrm{RO} / \mathrm{UF} / \mathrm{MF}$}

3.1 RO

Idris et al. [65] deduced the fine structural details of RO hollow fiber membranes (CA) subjected to $\mathrm{RO}$ using surface force-pore flow model. Hollow fibers were prepared from a dope containing CA $(27 \%)$ acetone $(42.8 \%)$ and formamide $(29.2 \%)$ by using dry/wet spinning technique. From thei study, they reached following conclusions:

1. Dope extrusion shear rate determines the general morphology of a fiber, i.e. pore size and the thickness of the active layer.

2. Rejection rate increases with increasing dope extrusion shear rate since the active skin thicknes and pore size of membrane decreases.

3. A minimum active layer thickness is desirable to maximise permeability.

4. It is likely that shear affects the phase separation inversion dynamics of membrane precipitation as well as the orientation of the polymer molecules in the active layer

\subsection{UF}

\subsubsection{Cellulose acetate $(C A)$}

Qin et al. [66] spun an outer skin hollow fiber UF membrane from a dope solution containing regenerated CA/PVP (360K)/NMP/water using the wet spinning technique.

The as-spun fibers were post-treated with a hypochlorite solution over a range of concentrations for a period of $24 \mathrm{~h}$. The experimental results showed that the pure water flux of the treated membrane increased with increasing hypochlorite concentration. An increase in hypochlorite concentration increased the fouling tendency of the treated membranes because of the decrease in hydophility due to the removal of a larger quantity of PVP in the mos be 列 which confirmed that addition of PVP favoured the suppression of macro-voids in the membrane The membrane pore size also depended on the hypochlorite concentration.

\subsubsection{Polysulfone (PSf)}

Soltys et al. [67] fabricated dual skin PSf hollow fiber membranes for ultrafiltration with thin skins on both the inner (lumenal) and outer surfaces of an annular matrix. These membranes had selectivity with sieving coefficients that were different in two flow directions (shell-to-lumen and lumen-to-shell). They suggested that the unique transport characteristics of those dual-skinned membranes could provide an extraordinarily powerful tool for design and development of novel membrane devices and processes that could exploit the directional selectivity of these new membrane membrane

It is well known that the surface chemistry and morphology play an important role in the performance of UF membranes. Surface-modifying macromolecules (SMMs) of low surface energy were used to modify the surface of UF membranes. Khayet et al. [68] has discussed the surface modification by SMMs and its applications in membrane separation processes. In the final product, SMMs migrated to the surface, and the fluorine end groups oriented themselves toward the air(17) span the spinning polymer interes an dope containing SMM added PSI/DMAc into hollow tibers by the dry wet spinning technique. The air-gap was varied from 10 to $90 \mathrm{~cm}$. Significant difference in surface morphology between the inner and the outer surface of the hollow fibers was observed by AFM. Similar results were obtained by contact angle measurement and XPS. Unexpected values of contact angles were obtained for both inner surface and outer surface. It was observed that the studied membranes could be put into two groups: (i) the membranes fabricated between 10 and $50 \mathrm{~cm}$ air gap and (ii) those fabricated at higher than $50 \mathrm{~cm}$ air gap.

Ishihara et al [69] developed non-fouling PSf hollow fiber membranes resistant to protein

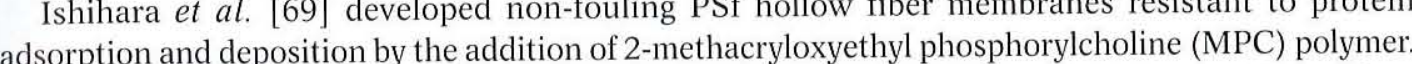
adsorption and deposition by the addition of 2-methacryloxyethyl phosphorylcholine (MPC) polymer. These membranes have an asymmetric structure and posses a good mechanical strength. The surface characterization of the PSf/MPC hollow fiber membrane by X-ray photoelectron spectroscopy revealed that the MPC units were concentrated at the surface. The permeability for solutes through the PSf $/$ MPC polymer membrane was higher, and the

Tan et al [70] prepared PSf asymmetric hollow fiber membranes with MWCO of 13,000 Da and Tan et al. [70] prepared PSf asymmetric hollow fiber membranes with MW (MG), brilliant green employed for removal of the triphenylmethane dyes including malachite green (MG), brilliant green (BG) and new fuchsin (NF) from aqueous solutions. Several water -soluble polymers such as poly (diallydimethyl ammonium chloride) (PDADMAC), poly(sodium-4-styrenesulfonate) (PSS) an The experimental results indicated that all the three triphenylmethane-type dyes could be removed The experion eflectively decorization of aG, BG and NF aqueous solutions.

\subsubsection{Polyethersulfone (PES)}

Chung et al. [11] studied the effect of the shear rate within the spinneret on morphology, separation performance and mechanical properties of hollow fiber membranes using PES material. It was reporte that an increase in shear rate increased the wall thickness, chain packing and solute separation, an decreased membrane flux when the shear rate is under a critical value. Above the critical shear rate, separation decreased slightly while the flux did not change. Chung et al. [71] also studied the effects separation de outer ol shear stress on the onter surface morphology of pes men 列 direction of dope extrusion at high shear rates. Roughness parameters decreased with an increase in shear rate. Pure water flux increased and the separation decreased with an increase in shear rate.

Wang et al. [72] investigated the effects of dope flow rate and flow angle within a spinneret during spinning hollow fiber membranes on the morphology, water permeability and separation performance of PES UF hollow fiber membranes. For this purpose, two spinnerets with different 
flow angles were designed and used, and wet-spinning technique was used to reduce the effect of gravity and elongation stress on the fiber. Experimental data suggested that higher dope flow rates (shear rates) in the spinneret produced UF fiber membranes with smaller pore sizes and denser skin layers due to the enhanced molecular orientation. Thus the pore size and water permeability decreased, but the solute separation increased. Hollow fibers spun from a conical spinneret had smaller mean pore sizes with larger geometric standard deviations, thus exhibiting lower water flux and greater solute separation than hollow fibers spun from a traditional straight spinneret. In addition, SEM analysis indicated that macrovoids response differently for the $90^{\circ}$ straight and $60^{\circ}$ conical spinnerets analysis indicated that macrovoids response differently for the $90^{\circ}$ straight and $60^{\circ}$ conical spinnerets
when the dope flow rate was increased. Macrovoids were significantly suppressed and almost disappeared in the $90^{\circ}$ spinneret at high dope flow rates. However, this effect was not observed for the $60^{\circ}$ conic spinneret.

Khare et al. [73] reported mathematical modeling on vapor-induced separation (VIPS) which involves a dry- wet casting process in which dope solution is exposed to a non-solvent vapor (often humid air) for a fixed time interval prior to immersion in a coagulation bath. PES/NMP/PVP dope was used for model calculation to fabricate UF/MF membranes.

Ochoa et al. [74] characterised the PES UF membranes with dopes containing different amounts of polyvinyl-pyrrolidone (PVP). It was observed that the addition of small quantities of PVP of different molecular weights to the spinning dope resulted in an increase of permeability without significant changes in selectivity.

Ameri et al. [75] fabricated PES hollow-fibers for water treatment by using the dry-wet spinning method. Fibers were heated in air at 120,150 and $180^{\circ} \mathrm{C}$. It was observed that membranes shrank by heating, which was evidenced by reduction in flux and increase in solute separation. The best results were obtained when the hollow fibers were heated at $150^{\circ} \mathrm{C}$. It was also observed that heating period affected membrane performance only little.

\subsubsection{Polyeherimide (PEI)}

Khulbe et al. [76] reported the structural and performance of micro-porous PEI hollow fiber membranes for ultrafiltration. Hollow fibers were prepared by the dry-wet spinning method using a solution of PEI in N-methylpyrrolidone (NMP) and $\gamma$ butyrolactone (GBL) (as an additive) at different air-gaps. Fibers were characterized by AFM. It was reported that as air-gap increased, the morphology of both surfaces, i.e. inner and outer surface, changed and also the performance. The pore size, pore size distribution and the roughness parameter of the hollow fiber depended on the air-gap. The nodule aggregates on both the inner and outer surface were aligned in the direction of the bore fluid (Figures 1 and 2)

Feng et al. [77] studied the structural and performance of micro-porous PEI hollow fibers prepared at different bore fluid flow rates using the dry-wet spinning technique. The pore sizes at the outer and inner surface of the hollow fibers were affected by the bore liquid flow rate. The bore liquid flow rate also influenced the UF performances of the hollow fiber membranes. The alignment of nodule aggregates to the direction of bore fluid was observed.

Xu et al. [78] studied the the morphologies and properties of hollow fibers (UF) obtained from PEI/DMAc. Fibers were fabricated by using the wet phase inversion technique. Effects of DMAc as a solvent additive in the bore solution (internal coagulant) and acetic acid as a non-solvent additive in the polymer dope on the morphologies and performances were investigated respectively. SEM results suggested that the addition of DMAc into the internal coagulant changed the inner fiber surface from dense skin layer to porous structure. However, the pure water flux of the membrane decreased with the increase of DMAc content. The addition of acetic acid into the casting solution promoted the spinodal demixing of the membrane-forming system and suppressed the macrovoid

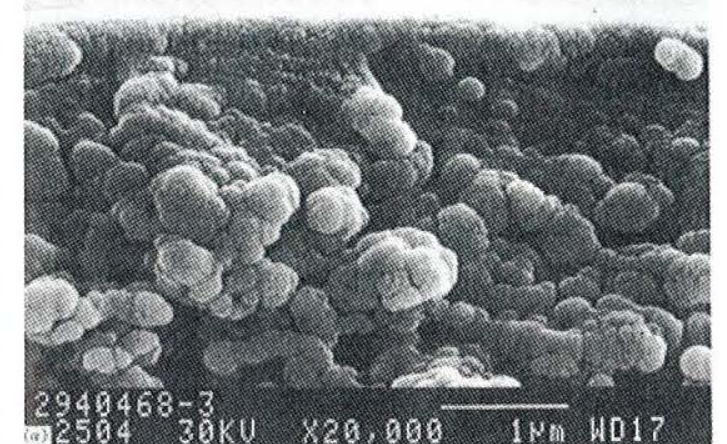

(a)

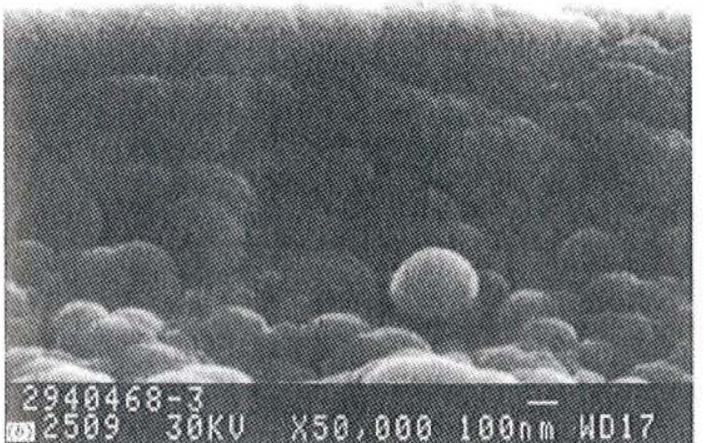

(b)

Figure 1 SEM photomicrograph of outer edge of a cross section of a hollow-fiber membrane spun from NMP/formamide: (a) $20 \mathrm{~K}$, (b) $50 \mathrm{~K}$. [165]

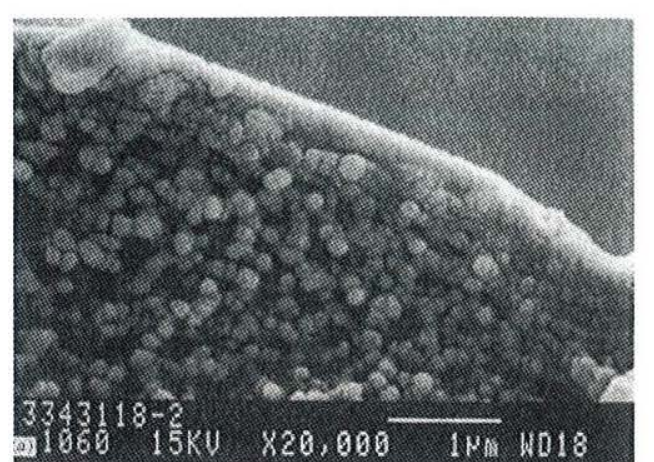

(a)

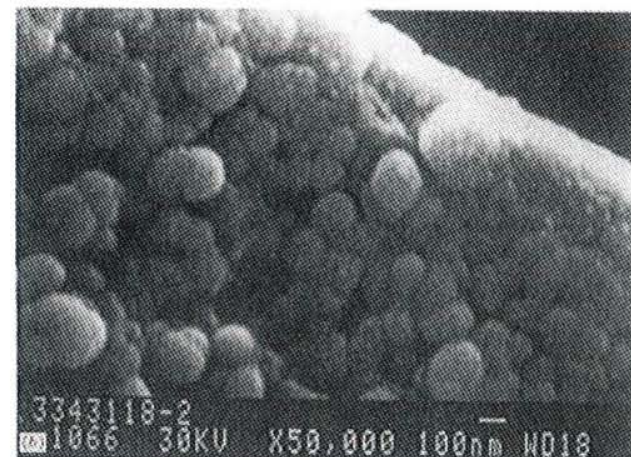

(b)
Figure 2 SEM photomicrograph of outer edge of a cross section of a hollow-fiber membrane spun from propionic acid: NMP:: (a) $20 \mathrm{~K}$, (b) 50K. [165]

formation in the membrane. Nodular structure was formed in the fiber skin layer. Pure water flux of the membrane increased about four times with increase of acetic acid in the dope. However, solute retention decreased slightly. The mechanical properties were improved slightly by this additive (acetic acid).

\subsubsection{Other Polymers}

Tasselli et al. [79] prepared hollow fibers (UF) of modified poly (ether ether ketone) (PEEKWC) via the dry-wet spinning technique. The effects of PVP in the dope solution and the effect of the humidity in the air gas-gap on the porosity, morphology, transport properties and mechanical properties of the membrane were investigated. On increasing the PVP concentration in dope solution the porosity and macro-voids decreased. However, an increase was noticed in dextran rejection. Improvement in mechanical properties in terms of tensile strength and elongation at break were also observed. The effect of humidity could be subdivided into two regions: (i) At the relative humidity lower than $100 \%$, the humidity had little influence on the morphology and on the transport properties of membrane. The pore size in the outer skin was below the SEM detection limit, and (ii) In an air-gap filled with supersaturated water vapor, pores with diameters of $0.2-1 \mu \mathrm{m}$ were formed and water 
permeation rates significantly increased. However in the latter case rejection of dextran was reduced to less than $2 \%$

In another article, Tasselli et al. [80] reported the effect of spinning parameters such as polymer concentration in the spinning solution, the air-gap and the bore fluid composition. The morphology of the cross-section and internal and external surfaces of the hollow fibres was investigated by using SEM. All membranes were shown to have a finger-like void structure and a skin layer, depending on the spinning conditions, varying from (apparently) dense to porous. Pore size measurements by the bubble-point method showed maximum pore sizes ranging from 0.3 to $2 \mu \mathrm{m}$

Khayet et al. [81] characterized the polyvinylidene fluoride (PVDF) hollow fiber UF membranes by using AFM, SEM, gas permeation tests, solute transport and liquid entry pressure of water measurements. The fibers were prepared by using the solvent spinning method. N,-Ndimethylacetamide was the solvent and ethylene glycol was employed as non-solvent additive. Ultrafiltration experiments were conducted by using polyethylene glycol and polyethylene oxides of different molecular weights as solutes. It was reported that the pore sizes determined by AFM, gas permeation test, and solute transport experiment, all increased as the concentration of ethylene glycol in the spinning solution increased and when ethanol was added to either the internal or external coagulant or both. The average pore size of the inner surface was larger than the average pore size of the outer surface. Nodules/nodule aggregates were observed at the inner and the outer surface of hollow fibers. Cross-sectional SEM pictures revealed that finger-like structures were formed when water was used as coagulant. On the other hand, a sponge-like structure appeared when a water/ ethanol mixture $(50 \% \mathrm{v} / \mathrm{v})$ was used either as internal or external coagulant.

Giorno et al. [82] fabricated polyamide hollow fiber membranes having nominal molecular weight cut-off (NMWCO) of $10 \mathrm{kDa}$ with an ID of approximately $1.5 \mathrm{~mm}$ and thickness of approximately $0.4 \mathrm{~mm}$ for the preparation of oil-in-water emulsions. In order to achieve permeation of the apolar organic solvent, isooctane, through the hydrophilic UF membrane it was necessary to pre-treat the membrane. The pre-treatment consisted in removing the polar internal liquid phase (water) and replacing it with the apolar solvent. The stability of membrane was very good, showing no decrease in performance for more than 3 months of contact with the organic solvent.

Korikov et al. [83] studied the performance of the interfacially polymerized (IP) hydrophilic thin film composite membranes on porous polypropylene (PP) hollow fibers. Commercially available hollow fibers (PPX-10, PPX-20, Celgard, Charlotte, NC, USA) were used. Hollow fiber membranes were characterized by measuring the reduction in solvent flux (70 vol.\% ethanol in water) and zein rejection. Zein is a corn protein that has a MW of 35,000 and belongs to prolamins, globular proteins which are insoluble in both pure water and alcohol, but soluble in 70-80\% alcohol solutions. These developed hollow fibers membranes were capable of $97 \%$ zein rejection from an ethanolic solution.

3.3 MF

Yang et al. [84] prepared isotactic polypropylene (iPP) hollow fiber micro-porous membranes via TIPS with a co-solvent di-n-butyl phthalate (DBP) and dioctyl phthalate (DOP). The DOP mass fraction in the co-solvent (a) and iPP mass fraction in the casting solution (p) were used as the variables in the spinning process. It was suggested that, for a crystalline polymer such as iPP, adjusting the competition between liquid-liquid phase separation and polymer crystallization is the proper approach to the formation of a membrane with an interconnecting pore structure and good performance.

Matsuyama et al. [85] prepared high-density polyethylene (HDPE) and low density polyethylene (LDPE) hollow fiber membranes from polyethylene-didodecyl phthalate solution using thermally induced phase separation (TIPS). The HDPE membrane showed about five times higher wate permeability than the LDPE membrane. It was reported that the HDPE membrane had larger pores and higher porosity at the outer surface in comparison with the LDPE surface. The explanation for forming larger pores was by the spinodal decomposition and the suppression of the diluents evaporation from the outer membrane surface due to the higher solution viscosity.

Fu et al. [86] prepared polymer blend hollow fiber membranes via thermally induced phase separation (TIPS). Poly(vinyl butyral) (PVB) and poly(ethylene-co-vinylalcohol) (EVOH) were used as polymers and the diluent was polyethylene glycol $(\mathrm{MW}=200)$. The addition of $\mathrm{EVOH}$ had an eminent effect on the hollow fiber membrane structure and membrane performance. With the increase of EVOH content in the polymer blend system, the membrane became more hydrophilic, and the water permeability became higher due to the enlargement of the pores. Addition of $\mathrm{EVOH}$ was also effective to improve the mechanical property of hollow fiber membrane

Faria et al. [87] prepared PEI (NMP as a solvent and PVP as an additive) hollow fiber by dry wet technique, and using water as non-solvent. It was reported that the membrane could be used successfully in the sterilization of fermentation media.

Luque $e t a l$. [88] studied microfiltration performance of a novel membrane module design with helically wound hollow fibers and compared with the data obtained with a standard commercialtype cross-flow module containing linear hollow fibers. Flux and capacity improvements of up to 3.2-fold (constant transmembrane pressure operation) and 3.9-fold (constant flux operation), respectively, were obtained with the helical module over those for the linear module.

Kobayashi and Hosaka [89] observed that the permeation flux of hollow fiber was enhanced when the MF membrane was placed into the vicinity of the reflection of $28 \mathrm{kHz}$ ultrasound. It was also observed that a semi-cylindrical reflection plate could highly enhance the membrane cleaning process.

\subsection{BIOMEDICAL (DIALYSIS, HEMODIALYSIS, ARTIFICIAL KIDNEY)}

\subsection{Cellulosics}

Broek et al. [90] characterized the hollow fiber hemodialysis membranes (Hemophan ${ }^{\circledR}$ ) by using a relatively new membrane characterization method, thermoporometry and concluded that this technique would be a strong tool for studying changes in pore morphology of these cellulosic membranes. Data obtained from this technique can be used to predict membrane performance. This method was developed by Brun et al. [48] based on the calorimetric analysis of liquid-solid transformation in liquid filled porous materials. From this technique, Hemophan was found to have a pore size distribution with pore radii between 1.5 and $12 \mathrm{~nm}$, and the volume porosity was $20 \%$.

Ye et al. [91] designed functional hollow fiber membranes with phospholipid polymers for application in total hemopurification system. The CA hollow fiber membranes (HFMs) modified with poly (2-methacryloyloxyethyl phosphorylcholine (MPC)-co-n-butyl methacrylate) (PMB30 and PMB80) were prepared by the dry-jet wet spinning process. Ye et al. [92] used cellulose acetate (CA) modified with poly (2-methacryloyloxyethyl phosphorylcholine (MPC)-co-n-butyl methacrylate) (PMB30 and PMB80) hollow fiber for hemo-purification.

\subsection{Polysulfone (PSf)}

Hayama et al. [93] measured the small surface pores of a hollow-fiber dialysis membrane (PSf) by different techniques. Table 2 shows a comparison of the average pore diameters of APS-150 membrane (Asahi-kasei, Japan) measured by FE-SEM (field emission scanning electron microscopy), TM-AFM 
Table 2 Comparison of average pore diameters determined by FESEM, TM-AFM and Hagen-Poiseuille equation

\begin{tabular}{|c|c|c|c|c|}
\hline \multirow[t]{2}{*}{ Observed portion } & \multicolumn{4}{|c|}{ Average pore diameter (nm) } \\
\hline & FESEM & $\begin{array}{l}\text { TM-AFM with } \\
\text { NCH }\end{array}$ & $\begin{array}{l}\text { TM-AFM with } \\
\text { SSS-NCH }\end{array}$ & $\begin{array}{l}\text { Hagen-Poiseuille } \\
\text { equation }\end{array}$ \\
\hline ASP-150 inside & 14.4 & 17.4 & 15.8 & 24.8 \\
\hline ASP-150 outside & 566 & 715 & - & \\
\hline
\end{tabular}

(tapping mode atomic force microscopy) with the probe $\mathrm{NCH}$ (silicon single-crystal probe, radius of curvature $=5-20 \mathrm{~nm}$ ), TM-AFM with the probe SSS-NCH (highly sharpened silicon single-crystal probe, radius of curvature $=2 \mathrm{~nm}$ ) and applying the Hagen-Poiseiulle equation. Data in Table 2 concludes that TM-AFM makes it possible to exactly observe the pores on the inside and outside surfaces of a hollow-fiber dialysis membrane, and the pore diameter is measurable accurately by image analysis.

Rafat et al. [94] characterized the PSf hollow fiber membranes used in artificial kidney by AFM SEM and contact angle measurement (CAM) with the aim of improving the membrane surface properties for blood compatibility. SEM microstructure studies demonstrated that the PSf hollow fibers had dense skin layers on both the interior and exterior surfaces. The ultrathin inner surface provided low resistance to solute permeability, which improved the separation performance, while the outer thin layer acted as an excellent barrier to blood endoxins. By increasing the drying time the roughness parameter and contact angle increased whereas the nodule size and the sizes of pores decreased. A theoretical model capable of predicting the effect of the surface morphology on contact angle was developed.

Lee et al. [95] reported the effects of the compositions of coagulant and spinning dope on the morphology and performance of PSf hollow fibers. PSf hollow fiber membranes were prepared via the dry-wet spinning process from the dopes comprised of PSf, NMP, polyvinyl-2-pyrrolidone (PVP) and dodecylbenzene sulfonic acid sodium salt. These membranes were subjected to hemofiltration. It was observed that morphology and performance of the membrane were affected by the compositions dope. The pore size and the addition of dodecylbenzene sulfonic acid sodium salt to water in the coagulation bath, due to changes of physiochemical properties of the outer coagulant. Addition of sodium salt of dodecylbenzene sulfonic acid to the dope also increased the pore size. In the absence of PVP, the pore forming agent, in the dope, a remarkable decrease in pore size of the membrane was observed. The air-gap (distance between the spinneret and coagulation bath) affected the membrane structure and performance.

Torto et al. [96] described a method for the in situ modification of hollow fiber membranes, by coating poly (ethylene imine), used as sampling units of microdialysis probes. The performances of PSf, PES, and polyamide membranes modified with poly(ethylene imine) (PEI)-enzyme complex were evaluated based on the membrane extraction fraction from maltose and maltotriose and membrane morphology was examined by SEM. Modification enhances the interaction of membrane with enzyme.

\subsection{Polyethersolfone (PES)}

Barzin et al. [97] studied PES hollow fiber membranes for hemodialysis by UF experiments and AFM. The membranes were prepared by using the dry-wet spinning technique from a dope consisting of PES/PVP $=18 / 3$ and $18 / 6$ by weight solution in N-N-dimethylacetamide (DMAc). Membranes were heated either in hot water $\left(95^{\circ} \mathrm{C}\right.$ for $\left.30 \mathrm{~min}\right)$ or in air $\left(150^{\circ} \mathrm{C}\right.$ for $\left.5 \mathrm{~min}\right)$. It was reported that the water flux of the hollow fiber increased significantly when heat-treated in water, while decreased water the other hand, MWCO of the hollow fiber increased slightly when heatwhen heat-treat while it decreased drastically when heat-treated in air. The roughness of both inne treated in water, while it dect or in air The membrane and outer surface decreased upon heat-treatment, either heated in wator or in heat-treated in air exhibited the lowest roughness. SEM images also showed that the surface morphology was different before and after heat-treatment. The hollow fiber membrane prepare from the blend ratio of PES/PVP $=18 / 3$ showed slightly higher flux than the hollow fiber membrane prepared from a solution with PES/PVP ratio of $18 / 6$. The performance data of the hollow fiber peated in air at $150^{\circ} \mathrm{C}$ was found to be the most appropriate for hemodialysis application. It was heated in air the tistributions. observed that the hollow fibers heat-reated in wa size distributions. The mean pore sizes were 16.3 But hollow fibers heated in air had narrow pore size distribution. The 18.6 and $3.8 \mathrm{~nm}$ for unheated, heated in water at $95^{\circ} \mathrm{C}$ and heated in air at $150^{\circ} \mathrm{C}$ hollow fiber prepared from $\mathrm{PES} / \mathrm{PVP}=18 / 6$, respectively, and $12.3,14.7$ and $3.1 \mathrm{~nm}$ for unheated, heated
.

\subsection{Other Polymers}

Ishikiriyama et al. [98] measured the pore size distribution (PSD) of polymer hydrogel membranes (s) such as pors porimetry. The PSDs of the poly(methyl methacrylate) membrane before and after freeze-drying were found to be quite different. poly (methyl methacrylate) membrane beflulose triacetate, polyacrylonitrile and PSf membrane were On the other hand, the PSDs of the cellulose triacetate, polyacrylonitrile and PSf membrane were
nearly similar before and after freeze-drying. Sugaya and Sakai [99] introduced polymethylmethacrylate hollow fibers for dialyzer.

\subsection{Theoretical Study}

Chung et al. [100] derived the basic equations for hollow fiber membrane formation from an Che equations derived were related to velocity profile of a nascent hollow fiber in the the air gap re simplified equations were also derived to and rheological parameres of predict the inner and outer diameter of hollow fiber. To prove their hypotheses, hollow fiber membranes were spun from 20:80 polybenzimidazole/polyetherimide dopes with $25.6 \mathrm{wt} \%$ solid in N,Ndimethylacetamide using water as the external and internal coagulants. They found that inner an outer diameters of as-spun fibers were in agreement with their prediction. Experimental data, such as SEM micrographs, gas separation performance, and CTE (coefficient of thermal expansion) abtained from the bolidity of the mathematical obtained from the hositive or negative effects on membrane model. Further formation and separation performance, depending on the process conditions. A high elongation stress may pull molecular chains or phase-separated domains apart in the early stage of phase separation and create porosity, whereas a medium stress may induce molecular orientation and reduce membrane porosity or free volume.

Shih et al. [101] presented a quantitative analysis, which describes the ternary diffusion proces enceric hollow-fiber membranes by the isothermal wet spinning encoun the mass trer equations both for process. Coordinate trans 
in the nascent membrane were found to agree with the membrane morphologies observed by electron microscopy.

During hollow fiber spinning many variables are involved whose effects are still not completely clear. The control of these variables may originate membranes with the desired morphologies and physical properties. Pereira et al. [102] verified that some of the variables involved in phase-inversion, could promote a visco-elastic polymer solution expansion, called die-swell phenomenon, which was undesired since it might lead to low reproducibility of the permeation properties. They investigated the effects of air-gap (distance between spinneret and coagulation bath), the bore liquid composition, and the polymer solution composition. According to their observations, it was concluded that the parameters investigated might promote a delay precipitation, which restrained the visco-elastic expansion.

Khare et al. [103] suggested a mathematical modeling on vapor-induced phase separation (VIPS) which involves a dry-wet casting process in which the casting dope is exposed to a non-solvent vapor (often humid air) for a fixed time interval prior to immersion in a coagulation bath. The extent and the rate of water transfer can be controlled by adjusting the velocity, relative humidity, and temperature of the air as well as the exposure time. By judicious combination of these variables, membranes with large pores at the top surface (surface contacted with water/vapor) can be obtained [104-108]

Goma-Bilongo et al. [109] developed a numerical model to represent the process by which hollowfiber membranes can undergo continuous surface modification by UV photografting. The model takes into account the coupled effects of radiation, mass transfer with polymerization reaction and heat transfer with evaporation. It gives approximately correct values for the mass of polymer grafted, but no attempt is made to relate this quantity with permeability or retention. The behavior of this complex model is used to explain how operating conditions can influence the result of the grafting process due to the modification by the hydrophilic MPC polymer:

Ye et al. [110] investigated theoretically the permeation time lag in polymeric hollow fiber membranes with the dual mode sorption isotherm and partially immobilized diffusion model. It was shown that curvature ratio (radius of outer surface/radius of inner surface of the hollow fiber) plays an important role for the permeation time lag in polymer hollow fiber membranes at intermediate pressure range.

Pan [111] demonstrated a mathematical model of multicomponent permeation systems with high flux, asymmetric hollow-fibers. The model took account of the permeate pressure variation inside the fiber: Laboratory and the technical feasibility of using the high flux asymmetric $\mathrm{CA}$ hollow fibers for $\mathrm{H}_{2}$ $\mathrm{CO}_{2}$ and $\mathrm{H}_{2} \mathrm{~S}$ separation. It was shown that the selectivity of the $\mathrm{CA}$ membrane was ideally suited to the recovery of the hydrogen gas from the purge gas of reactor cycle loops. For the separation of high concentration of $\mathrm{CO}_{2}$ or $\mathrm{H}_{2} \mathrm{~S}$ gas, the test data showed that the permeabilities of the individual components in mixed gas were significantly different from those of pure gases

Gabelman and Hwang [112] made a general review of hollow fiber membranes contactors, including operating principles, relevant mathematics, and applications. A theoretical study of dense gas extraction using a hollow fiber membrane contactor has been also made [113, 114]. Mi and Hwang [115] discussed a general theory relating to the hydrodynamic parameters, mass transfer coefficient, and concentration polarization for mass transfer in a hollow fiber module. The effect of flow dynamics on polarization was also discussed.

Song et al. [116] used the porous hydrophobic polypropylene hollow fibers coated with a porous fluorosilicone on the outer surface of hollow fiber for the desalination and used direct contact membrane distillation technique. They demonstrated a model using the mass transfer coefficient an adjustable parameter predicted the brine temperature drop, distillate temperature rise, and water vapour flux well for the large module and smaller module of $119-\mathrm{cm}^{2}$ area.
4.6 Patents

Macheras et al. [117] patented a method and apparatus of spinning hollow fiber membranes for fluid separation. In this patent they also claimed these membranes can be either anisotropic, most flequently asymmetric, or isotropic, and may be useful for a variety of fluid separation, including gas frequently aration.

Puri [118] described a method for the preparation of a composite hollow fiber membrane for the Puri [118] described a method for the preparation of a composite hollow fiber menty passed through separation for gas or liquid. In his method, the hollow tiber substrate is continuous porm a uniform a polymeric coating solution and withdrawn from a solution through a coating die to form a uniform polymeric solution coating on the outer surface of the hollow fiber. The portion of the solvent from the coating is allowed to evaporate thereby forming a thin, dense surface layer after which the remaining solvent from the coating layer is leached out.

Mach membranes from blend polymers.

Lee and Le [120] Lee and Lee [120] invented a nanocosin (2) coated on It included a reinforcement (1) which was a tubular bramide active layer (3) formed on the outer the outer surface of the reinforcement (1), and a polyamide advantage of an excellent strength and surface of the polymeric resin thin film. This invention has an

an increase in membrane area relative to an installation area. Klotzer et al. [121] patented a method of producing porous trovided in an extrusion apparatus. where a molten polymer charged with a gas under pressure was frov the extrusion apparatus through The polymer melt including the gas under pres

a hollow fiber-forming extrusion nozzle.

Kakiuchi et al. [122] patented a hollow fiber made of ethylene-vinyl alcohol polymer (EVA) that comprised a dense layer existing in the inner surface and a porous layer existing in the layer other than the dense layer. The membrane was subjected to hemopur

hemodiafiltration, hemofiltration and continuous hemonf fabricated from perfluorinated thermoplastic

Cheng et al. [123] patented a high flux fiber membrane fabricated from pertical solution temperature polymers by extruding a heated solution of the polymer having a lower critical solution temperation. Extrusion directly into a cooling bath to form the porous mem

\subsection{HOLLOW FIBERS FOR MISCELLANEOUS APPLICATIONS OR WITHOUT} SPECIFIC APPLICATIONS

\subsection{For Miscellaneous Applications}

Gao et al [124] developed a technique i.e. consecutive solvent evaporation and co-rolling for polymer core photonc fibe fon multilayer for hollow core photonic fiber formation. The fabrication process intive indices followed film deposition from a solvent phase of two polymers with high and low refrative by solvent evaporation on the inside of a rotating PMMA or polycarbonate tube, used as a cladding material. By injecting right volumes of the polymer solutions into a spinning tube the thickness of the

Qi and Qi and Lee [125] de capillary electrophoresis. MMA (polymethylmethacrylate) (using graft copolymic hollow fibers for the degradation of phenolic Guibal et al. [126] fabricated chitosan catalytic hollow fibers for the degradation of phenolic
derivatives. Hollow chitosan fibers were prepared by extrusion of chitosan into a coagulating solution 
followed by a final conditioning step to increase the stability of chitosan in acidic solutions. The fibers were then contacted with Pd solution at $\mathrm{pH}$ 2. The Pd loaded hollow fiber was finally reduced with $\mathrm{Zn}$ powder in contact with sulfuric acid solution

Gao et al. [127] fabricated catalytic polymeric hollow-fiber reactors for the selective hydrogenation of conjugated dienes. The hollow fibers were prepared from PVP-Pd/CA, PVP-Pd/PSf, PVP-Pd/ $\mathrm{PAN}, \mathrm{EC}-\mathrm{Pd} / \mathrm{CA}$ and AR-Pd/CA $(\mathrm{EC}=$ ethyl cellulose, $\mathrm{AR}=$ melamine-formaldehyde resin, $\mathrm{CA}=$ cellulose acetate, PAN = polyacrylonitrile) by supporting the soluble polymer anchored palladium complexes of PVP-Pd, EC-Pd and AR-Pd on the corresponding CA, PSf and PAN hollow fibers, respectively. Selective hydrogenation of conjugated dienes was carried out in reactors under mild conditions of $40^{\circ} \mathrm{C}$ and $0.1 \mathrm{MPa}$. All of the catalytic hollow fibers were active and stable for the hydrogenation of conjugated dienes.

Moeder et al. [128] demonstrated the degradation of hydroxylated aromatic compounds using laccase and horseradish peroxidase immobilized on microporous polypropylene hollow fibe membrane.

Basheer et al. [129] used the DHPMM (dihydroxylated polymethylmethacrylate) coated hollow fiber for the microextraction of trace amounts of neutral and synthetic estrogens such as diethylstilbestrol, estrone, $17 \beta$-estradiol and $17 \alpha$-ethynylestradiol in water sample followed by GCMS analysis.

Song et al. [130] tested fibers made of PP, polyetheretherketone (PEEK), polyethylene terephthalate (PET) and PES for heat-exchanger Combined with the much lower cost, lower weight and elimination of metal contamination, they recommended these membranes can be applied in the fields of food, pharmaceutical and biomedical industries as well as application where corrosion resistant, light and very efficient devices are required, i.e. desalination, solar and offshore heat transfer application.

Liu et al. [131] used polymeric hollow-fibers prepared from poly propylene and polybutylene terephthalate used as capillary electrophoresis (CE) columns for the separation of substituted pyridines, model proteins and standard ribonucleotides. The practical potential of small diameter polymeric hollow fibers as $\mathrm{CE}$ columns was evaluated.

Bqyqktuncel et al. [132] used poly (vinylalcohol) coated/cibacron blue F3GA-attached polypropylene hollow fiber membranes for removal of cadmium ions from aquatic systems.

Sakai and Matsunami [133] developed polypropylene hollow fiber membrane for plasma separator The developed membrane has regular and orderly rectangular pores. The final product was named Propylex (Ube Industries Ltd.). This product was characterized by: (i) low complements activation because it is polypropylene membrane; little damage to blood cells even under high trans-membrane pressure due to its characteristic pore structure, and (iii) slight fluctuation in the sieving coefficients for substances with high and low molecular weights with increased throughput, which allows stable clinical use.

\subsection{Hollow Fibers without Specific Applications}

Kusumocahyo et al. [134] developed a new approach for the preparation of polymer inclusion membrane (PIM) to produce hollow fiber PIM. The authors called the new method the post treatment method. In this method a cellulose triacetate (CTA) hollow fiber was allowed to swell in 2-nitrophenyln-octyl ether (NPOE) in the presence of chloroform as a solvent for CTA and N,N,N1,N1-tetraot 3-oxapentane diamide (TODGA) as a caures. After evaportion of chloroform, a hollow fiber PIM was effective to transport cerium ions from the feed phase to the strip phase. They claimed this was the first PIM developed in hollow fiber configuration.
Fujii et al. [135] studied the morphological structures of hollow fiber membranes by high resolution field emission scanning electron microscopy. The studied membranes were the hollow fibers of nine polymers including a copolymer, a cellulose acetate asymmetric RO membrane and membranes of acrylonitrile-sodium p-styrenesulfonate copolymers. In all membranes, the structure composed of agregated polymeric spheres was observed (outer surface and cross section). The spheres had diameters of seve diameters of severat nano contours of the spheres and interstices were clearly observed. It was concluded that the permanen pores were the remaining openings between the imperfectly fused spheres. The pore sizes estimated from the sphere diameters corresponded to the pore diameters observed. It was concluded that the molecules of water and solutes permeate the membrane mainly through interstices between the polymeric spheres. Their observations supported that mass transport behavior through such membranes should be described in terms of a capillary model.

Chung and $\mathrm{Hu}$ [136] reported that the hollow fibers prepared by dry-wet spinning from the PES/ NMP dope first go through a moisture-induced phase separation process and then a wet phase inversion process, resulting in external fiber skins that have a short range random, compact and lightly oriented or stretched structure.

Qin [137] reported that there is a potential to fabricate defect-free hollow fiber fluorinated polyimide composite membranes.

Weigel et al. [138] showed that the properties of PAN membranes can be improved by plasma treatment.

Saufi and Ismail [139] reported the development and characterisation of polyacrylonitrile (PAN) based carbon hollow fiber membrane. PAN membranes were pyrolized at temperature between $500^{\circ} \mathrm{C}$ and $800^{\circ} \mathrm{C}$ for 30 minutes in presence of nitrogen. Membranes morphology and performances were studied by SEM, Fourier Transform Spectroscopy (FTIR) and gas sorption analysis. Pyrolysis temperature was found to significantly change the structure and properties of carbon membranes.

Xiuli et al. [140] studied the morphological structure and properties such as, miscibility, tensile Xiven flux and retention atio of hollow fiber membranes prepared from spinning dopes made of a spinning solution composed of polymer (PAN:PVDF $=10: 0,9: 1,7: 3$ ), additive (PVP, PEG-600) and solvent (DMAc). The morphology of membranes was examined by SEM. The blend membranes possessed much higher flux than PAN membrane and fairly good retention ratio especially for the membrane made by PAN:PVDF $=9: 1$.

Mei et al. [141] studied the morphological structure of polypropylene/easy hydrolytic degradation polyester (PP/EHDPET) hollow fiber membranes fabricated by blend-spin and cold stretch process. PP/EHDPET is an incompatible blend system and can form a two phase structure. They reported that PP component as continuous phase (sea) and EHDPET component as dispersed phase (island) in the final product as observed by SEM. During the cold stretching process, the sea and island phases of the blend fiber separated along the fiber surfaces and interfaces to a form micro-porous structure.

Hong et al. [142] reported that on contacting a cast or spun polymer solution with water or organic vapor prior to immersion into a non-solvent precipitation medium, higher permeability an excellent rejection can be obtained.

Kong and $\mathrm{Li}$ [143] developed an improved gas permeation method for the characterisation of microporous asymmetric hollow fiber membranes. Based on this technique, the membrane pore structure parameters such as mean pore size, pore size distribution and effective porosity of the microporous asymmetric membrane can be determined from membrane gas permeation data using either standard normal or log-normal distribution functions. The predicted permeation coefficients were found to be in good agreement with the actual experimental data

Li and Xino [144] studied structure and properties of composite polyurethane-silica hollow fiber membranes. The experimental results indicated that $\mathrm{SiO}_{2}$ in membrane created a great many interfacial 
micro-voids and played an important role in the performance of membrane. With the increase of $\mathrm{SiO}_{2}$ content, PWF increased and the rejection decreased slightly.

\subsection{Triple-Orifice Spinneret}

In recent years, the triple-orifice spinneret has been developed, in which a bore liquid, a internal polymer solution, and an external polymer solution (or an external liquid) are simultaneously extruded. By variation of this external liquid different types of morphologies were prepared such as dense membranes for gas separation [145], pervaporation [146] and porous membranes for ultrafiltration [147]. Henne et al. disclosed the first dual-layer asymmetric hollow fiber composite membrane for hemodialysis [148]. After that many patents have been issued regarding double layer composite membranes [149-152]. Suzuki et al. [153] applied the co-extrusion approach to prepare composite hollow fibers with a dense outer layer of poly(ethylene oxide)-containing polyimide on a sponge support layer of other polyimide for gas separation.

\subsection{Bore Liquid/Internal Polymer Solution/External Polymer Solution}

Li et al. [154] developed a fluoropolyimide/PES delamination free dual-layer asymmetric composite hollow fiber membrane subjected for gas separation. For concept demonstration, a 6FDA-durene1,3-phenylenediamine (mPDA) (50:50) copolyimide was used to form outer asymmetric separating layer, while PES was employed to yield the inner interpenetrated porous supporting layer. The effects of spinning conditions, such as spinneret temperature, air-gap, bore fluid chemistry, inner layer dope concentration and formulation, and solvent exchange, on the interface delamination between the dual layers were examined. Inner-layer dope concentration and bore fluid composition as well as the sequent solvent exchange were found to play important roles to produce delamination-fre-duslayer menbranes had an $\mathrm{O}_{2} / \mathrm{N}_{2}$ selectivily approaching layer membranes had an $\mathrm{O}_{2} / \mathrm{N}_{2}$ selectivity approaching to the intrinsic ideal selectivity value of 4.7 with a permeance of oxygen around $28 \mathrm{GPU}$ at room temperature, indicating that the dual layer hollow fiber membranes were apparently defect free.

Li et al. [155], by using Matrimid ${ }^{\circledast} 5218$ as the outer layer material and PES and its blends as the inner-layer materials, produced dual-layer hollow fiber membranes. In this paper authors discussed the science and engineering factors to fabricatedual-layer asymmetic ho structure under various spinning conditions. Delamination phenomenon was explained on the basis of the interfacial structure (the difference in shrinkage percentage of both layers). The influence of delamination on the surface structure of both inner and outer layers was determined.

Li et al. [156] fabricated dual layer PES hollow fiber membranes (both inner layer and outer layer were PES.) by co-extrusion and dry-jet wet spinning phase-inversion techniques with the aid of heat-treatment at $75^{\circ} \mathrm{C}$. They claimed that this was the thinnest structure (ultathin dense-secte layer of $407 \AA$ ) ever report permeation of $10.8 \mathrm{GPU}$ and $\mathrm{O}_{2} / \mathrm{N}_{2}$ selectivity of 6.0 at $25^{\circ} \mathrm{C}$. It was found that heat treatment a $75^{\circ} \mathrm{C}$ improved the gas permeance and ideal selectivity, while heat treatment at $150^{\circ} \mathrm{C}$ resulted in significant reduction in both permeance and selectivity due to the enhanced substructure resistance. SEM confirmed that high temperature can significantly reduce pore sizes and the number of pores in the sub-structure immediately underneath the dense-selective layer.

Pereira et al. [157] studied the morphology of the hollow fiber membrane obtained by simultaneous spinning of two polymer solutions using a triple orifice spinneret. Polyetherimide (PEI) and polyethersulfone (PES) were used as base polymers. A polymer solution composed of Lewis acid:base complex (adipic acid-Lewis acid, and NMP-Lewis base) and another composed of a macromolecula additive (polyvinylpyrrolidone) were used in order to form the support layer. Different polymer solutions composed of a different volatile component (tetrahydrofuran) were used for the top layer They compared the structures of dual layer asymmetric hollow fiber membranes with those of single layer ones. This process presents several benefits such as possibility of forming each membrane layer layer ones. This process

by different concepts.

Yang et al. [158] fabricated asymmetric annular hollow fiber membranes by co-extrusion of PES/ PVP polymer blend and PVDF with a triple orifice spinneret. The successful formation of annular hollow fiber membrane was due to the use of two partially immiscible polymer solutions and differen shrinkage ratios of two layers. Addition of a small amoune morphology of the outer layer of the annula hollow fiber membrane. From this study it was concluded that the annular hollow fiber membranes have great potential for the use in immobilization/entrapment of biocatalyst for biochemical reaction.

\subsection{Bore Liquid/Polymer Solution/External Liquid}

He et al. [159] prepared highly porous PSf hollow fiber membranes with a triple orifice spinneret. Considering the general rules of diffusion induced phase separation, a low polymer concentration is required at the outer layer to obtain a highly interconnected open porous structure. By using NMP as the external liquid at the outside orifice of the spinneret, a highly porous surface can be obtained at the outer surface. To prepare PSf MF membranes with a highly porous surface, dilution solvents (5) external liquids during spinning to independent of polymer solution in spinning process is to apply a good solvent as the external liquid using a triple-orifice spinneret. A polymer solution close to the cloud point does not show significant improvement in permeability since the surface pores are open enough and not the controlling parameter for transport. However, a porous surface can be obtained for a polymer solution far from the cloud point, forming a dense skin layer but an open substructure, such as a solution of PSf and PVP.

Albrecht et al. [160] analyzed SEM results of the morphology of PEI hollow fibers membranes

Albrecht et al. [160] prepared by the dry-wet spinning technology. It was reported that the ou layer of the extruded polymer solution could be precipitated by vapor induced phase separation (VIPS), resulting in a relatively dense structure. In order to avoid VIPS, a modified air-gap spinning process was developed using a triple spinneret where the outer annulus was used to the transport of fluids containing a high amount of solvent. As a consequence of the presence of fluid at the outer surface of the nascent hollow fiber, the polymer concentration was locally reduced and the fiber was protected against the corption of asymmetric hollow fiber morphologies without any external skin could be reproducibly prepared.

5.6 Application of Response Surface Methodology and Factorial Design in Hollow Fiber Membrane Development

A factorial design is a design of experiments used to evaluate two or more factors simultaneously The advantages of factorial designs over the one-variable-at-a-time approach are that they are more efficient and they allow interactions between factors to be detected. An excellent source of basic information about the process of factorial design is the book named Statistics for Experiments by Box et al. [161].

Wood [162] studied the PPO hollow fibers prepared by the dry-wet technique for the separation of $\mathrm{CO}_{2}$ and $\mathrm{CH}_{4}$. The polymer solution was PPO in trichloroethylene with 2-ethyl-1-hexanol as an 
additive. Methanol as a non solvent was used in the bore fluid and in the gelation bath. The variable studied were the length of the air-gap, the flow-rates of the bore fluid and the polymer solution, and the presence of 2-ethyl-1-hexanol. From the factorial design it was observed that the interation between the presence of 2-ethyl-1-hexanoland the bore fluid flow-rate had a significanteffect on the hollow fiber wall thickness. None of the interaction between the othe significant effect on the other variables was found to have significant effect on the hollow fiber dimension. The results were used to develop models for each of the five response variables as a function of those spinning variables that were found to be significant. Idris et al. [163] studied CA hollow fiber membranes for RO. Hollow fibers were spun using a forced convection technique. In their study the experimental design was based on fractional factoria method and results were discussed accordingly. The factors considered in the experimental design included the polymer contents, the ratio of the solvent (acetone) to swelling agents (for he dope solution, the dope extusionate, the type of bore fluid, the residence toge, (for a the dope solution, the dope extrusion rate, the type of bore fluid, the residence time, and the nitrogen gas flushing rate. The results indicated that the bore fluid and the dope extrusion rate were the mos important factors in determining the performance of the RO membranes.

Koros school [164] studied the effects of spinning conditions on the morphology and performance of integrally skinned hollow fiber membranes (PSf) for gas separation. Statistical experimental designs were used to optimize the permeation properties of these fibers which were prepared by the dry/wet phase separation process. A complete $2^{4}$ factorial design exs etion properties and torr pares membranes. Influence of water activity was investigated for both water/salt and water/solvent mixtures. The permeation properties of the hollow fibers appeared to be dependent only on the water activity of the bore fluid and independent of the type of bore fluid; salt solutions allowed access to lower water activities than solvent solutions because both the salt and water are nonsolvent for polysulfone.

\subsection{Cross-sectional Images (Wall of the Hollow Fiber)}

Kesting and Fritzche [165] studied the cross-sectional structure of PSf hollow fibers by SEM. Figures 1 and 2 are the SEM pictures of the outer edge of the hollow fibers spun from formamide/NMP solvent and propionic acid/NMP solvent, both at 25 and $50 \mathrm{k}$ magnification, respectively. The hollow finers spun from formamide/NMP reveals a thick dense skin of approximately $400 \mathrm{~nm}$. The skin is composed of nodule aggregates so tightly packed at the surface that their boundaries are not discernible. Beneath this layer the individual nodule aggregates become more readily identifiable, but remain tightly packed assembly. The skin layer of the hollow fibers spun from propionic a NMP is thinner than the skin of the former hollow fibers. Again, bethe the agregates of the skin layer, less tightly packed of the latter hollow fibers was ascibed to the larger size of of the latter hollow fibers was ascribed to the larger size of the Lewis acid-base complex that was working as a temporary template. Similar SEM images and differences were also observed by others with different polymers and solvent used [166, 167].

Khulbe $e$ al. [178] conducted an AFM study of the cross-section of UF polyetherimide (PEI) hollow fibers, fabricated by the dry-wet spinning method at various air-gaps. Even though it was difficult to produce a smooth surface area of sufficiently large size by siling the fiber with a shas edge (razor blade) or fracturing the fiber at liquid nitogen la obtaining AFM imges at less than 3 m scan obtaining AFM images at less than $3 \mu \mathrm{m}$ scan ranges. The thickness of the fiber wall was in the range from 76 to $68 \mu \mathrm{m}$. Figure 3 shows the AFM image (scan range $2 \mu \mathrm{m}$ ) of the middle section of the wall of a hollow fiber that was fabricated at $50 \mathrm{~cm}$ air gap. From Figure 3 it appears that there are spheres in the cross-section, which are nodules. Some nodules are fused with each other to form nodule aggregates. In Figure 3 there are dark areas, which may be macro-voids, or paths of pores that are

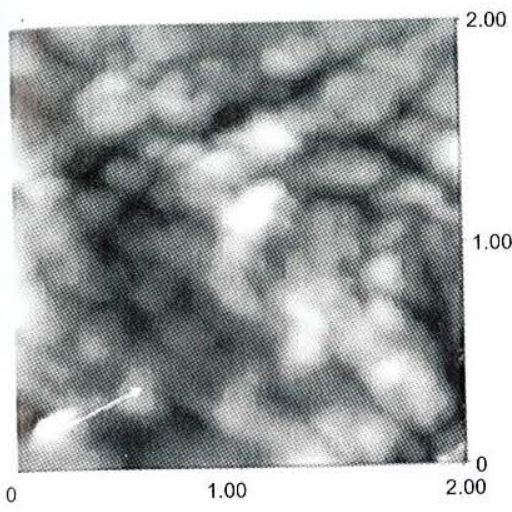

Figure 3 AFM image of the cross section of the hollow fiber's wall fabricated at $50 \mathrm{~cm}$ air gap (samples were prepared by cutting

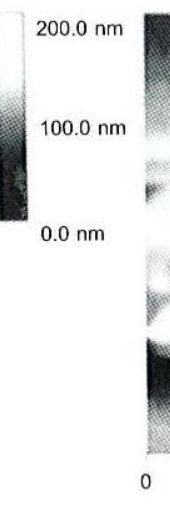
Figure 4 AFM image of the cross section near the fabricated at $30 \mathrm{~cm}$ air gap (samples were sharp edge) [168] prepared by cutting the hollow fiber by a

commonly observed by AFM. Figure 4 shows the cross-section of the wall of a hollow fiber fabricated commonly observed by AFM. Figure 4 shows the cross-section of the wall of a hollow tiber fabricated at a $30 \mathrm{~cm}$ air gap. There are layers of nodules in rows, but in the middle section there is a long dark area of a finger like macro-void. This is commonly observed in hollow fibers. Similar images were also obtained for other hollow fibers at different air-gaps. In summary, the following observations were made on the morphology of the PEI hollow fibers fabricated by the dry wet spinning technique.

(1) The AFM images were similar to those observed by TSEM (Fujji et al. [168]) for other polymeric hollow fibers.

2) The cross-section near the inner layer contained well-defined nodules with a smaller number of nodules and nodule aggregates.

(3) The maximum nodule size occurred in the middle section

(4) Nodules were aligned in rows to the angular direction in the inner, middle and outer section of the hollow fiber cross-section,

The area near the outer surface was very porous and nodules were fused with each other. Very few isolated nodules were observed.

\section{CONCLUSIONS}

From this survey the following conclusions can be drawn

(1) Hollow fibers were fabricated mostly from the polymers that have been used successfully for the formation when slightly different from the casting conditions of flat sheet membranes.

(2) Nevertheless, some novel polymers were spun into hollow fibers.

(3) Hover fesaration, desalination, wate treatment, and artificial organs. However, there are some hollow fibers that have been applied for membrane contactor, pervaporation and vapour permeation. 
(4) Regarding hollow fibers for reverse osmosis, few attempts have been made in the formation of thin film composite (TFC) membranes by in-situ polymerization. Considering the fact that the

5) Unlike flat sheet membranes, the effects of roughness at the hollow fiber surfaces on the membrane flux and fouling have not been studied.

(6) Cross-sectional images of hollow fibers are mostly obtained by SEM. AFM was used only recently to observe the cross-section of hollow fibers.

(7) Despite the complicated interplay of many factors that affect the hollow fiber fabrication, some theoretical models were developed. Application of factorial design seems a powerful tool.

(8) Triple-orifice spinneret is intensively studied by a few groups. This may become a useful tool to control the external skin layer.

Despite many advantages of hollow fibers over the flat sheet membranes, there are some serious disadvantages. One of them is severer fouling of hollow fibers particularly when the feed solution enters into the bore side. In order to reduce the fouling hollow fiber surface modification and roughness effect on fouling have to be studied more thoroughy. Another disadvatte me polyuctic hollow fibers is that it overcome by the development of ceramic hollow fibers, which is however out of the scope of thi review.

\section{REFERENCES}

[1] Mahon, H.I., and E.A. McLain. 1968. Permselective Hollow Fibers and Method of Making. Ca Patent 786,719.

[2] Mclain, E.A., and H.I. Mahon. 1969. Permselective Hollow Fibers and Method of Making Us Patent 3,423,491.

[3] Geary, J.E. Jr. 1969. Method of Manufacture of Fluid Separation Apparatus. Us Patent 3442002 Geary, J.E. Jr. 1969. Centrifugal Casting Apparatus for Forming a_Cast Wall Member Extending Transversely Across an Elongated Bundle of Substantially Parallel Hollow Filaments of A Fluid Permeation Separation Apparatus. Us Patent 3492698.

[5] Henis, J.M.S., and M.K. 1980. Tripodi. Multicomponent Membranes for Gas Separation. US Patent 4230463

[6] Hoehn, H.H. 1984. Aromatic Polyamide in Materials Science of Synthetic Membranes. D.R Lloyd, Ed. ACS, Washington D.C.

[7] Cabasso, I., E. Klein, and J.K. Smith. Polysulfone Hollow Fibers. I. Spinning and Properties. 1976. J. Appl. Polym. Sci. 20(9): 2377-2394.

[8] Loeb, S. and S. Sourirajan. 1962. Adv. Chem. Ser. 38: 117.

[9] Mulder, M. 1993. Basic Principles of Membrane Technology. Dordrecht. The Netherlands: Kluwer Academic Publishers.

[10] Berghmans, S., H. Berghmans, and H. Meijer. 1996. Spinning of Hollow Porous Fibres via the TIPS Mechanism. J. Membr. Sci. 116: 171-189.

[11] Chung, T.S., J.J. Qin, and J. Gu. 2000. Effect of Shear Rate Within the Spinneret on Morphology, Separation Performance and Mechanical Properties of Ultrafiltration Polyethersulfone Hollow Fiber Membranes. Chem. Eng. Sci. 55: 1077-1091.

[12] Gerlach, K. and E. Kessler. 1986. Methods for the Preparation of Porous Fibers and Membranes. US Patent 4,564,488.
[13] Mckelvey, S.A., T. Domonic, D.T. Clausi, and W.J. Koros. 1997. A Guide to Establishing Hollow Fiber Macroscopic Properties for Membrane Applications. J. Membr. Sci. 124: 223-232.

[14] Kesting, R.E., A.K. Fritzsche, C.A. Cruse, and M.D. Moore. 1990. The Second-generation Polysulfone Gas-separation Membrane. II. The Relationship Between Sol Properties, Gel Macrovoids, and Fiber Selectivity. J. Appl. Polym. Sci. 40: 1575-1582.

[15] Fritzsche, A.K., C.A. Cruse, R.E. Kesting, and M.K. Murphy. Hollow Fiber Membranes Spun from Lewis Acid: Base Complexes. I. Structure Determination by Oxygen Plasma Ablation. 1990. J. Appl. Polym. Sci. 40: 19-40.

[16] Fritzsche, A.K., C.A. Cruse, R.E. Kesting, and M.K. Murphy. 1990. Polysulfone Hollow Fiber Membranes Spun from Aliphatic acid $\left(\mathrm{C}_{2}-\mathrm{C}_{4}\right): N$-methylpyrrolidone Complexes - Structure Determination by Oxygen Plasma Ablation. J. Appl. Polym. Sci. 41: 713-733.

[17] Fritzsche, A.K., B.L. Armbruster, P.B. Fraundorf, and C.J. Pellegrin.1990. The Structure of the Effective Separating Layer of Asymmetric Hollow Fiber Membranes with Graded Density Skins J. Appl. Polym. Sci. 39: 1915-1932.

[18] Ismail, A.F., I.R. Dunkin, S.L. Gallivan, and S.J. Shilton. 1999. Polymer. Production of Super Selective Polysulfone Hollow Fiber Membranes for Gas Separation. 40: 6499-6506.

[19] Ismail, A.F., M.I. Suhaina, and N.S. Nasri. 2002. Effects of Dope Extrusion Rate on the Morphology and Gas Separation Performance of Asymmetric Polysulfone Hollow Fiber Membranes for $\mathrm{O}_{2} / \mathrm{N}_{2}$ Separation. Songklanakarin. J. Sci. Technol. 24 (suppl): 833-842.

[20] Gordeyev, S.A., G.B. Lees, L.R. Dunkin, and S.J. Shilton. 2001. Super-selective Polysulfone Hollow Fiber Membranes for Gas Separation: Rheological Assessment of the Spinning Solution. Polymer. 42 (9): 4347-4352.

[21] Bhardwaj, V., A. Macintosh, I.D. Sharpe, S.A. Gordeyev, and S.J. Shilton. 2003. Polysulfone Hollow Fiber Gas Separation Membranes Filled with Submicron Particles. Ann. NY Acad. Sci. 984: 318-328.

[22] Wang, D., W.K. Teo, and K. Li. 2002. Preparation and Characterization of High-flux Polysulfone Hollow Fibre gas Separation Membranes. J. Membr. Sci. 204: 247-256.

[23] Wang, D., W.K. Teo, and K. Li. 2004. Selective Removal of Trace $\mathrm{H}_{2} \mathrm{~S}$ from Gas Streams Containing $\mathrm{CO}_{2}$ Using Hollow Fibre Membrane Modules/contractors. Sep. Purif. Technol. 35: $125-131$

[24] Clausi, D T and WJ. Koros. 1997. A Rapid Feedback Characterization Technique for Polymeric Hollow Fiber Membranes Using Disperse Dyes. J. Membr. Sci. 129: 237-242.

[25] Horváth, R., T. Orosz, B. Bálint, M. Wessling, G.H. Koops, G.C. Kapantaidakis, and K. BélafiBakó. 2004. Application of Gas Separation to Recover Biohydrogen Produced by Thiocapsa Roseopersicina. Desalination. 163: 261:265.

[26] Qin, J.J., T.S. Chung, W. Lin, and J. Gu. 2005. 229 ACS Meeting, San Diego, CA March13-17 (Abstract No. 63)

[27] Wang, D., K. Li, and W.K. Teo. 2000. Highly Permeable Polyethersulfone Hollow Fiber Gas Separation Membranes Prepared Using Water as Non-solvent Additive. J. Membr. Sci. 176: 147158.

[28] Wallace, D.W., C. Staudt-Bickel, and J.W. Koros. 2006. Efficient Development of Effective Hollow Fiber Membranes for Gas Separations from Novel Polymers. J. Membr. Sci. 278: 92-104.

[29] Chung, T.S. and E.R. Kafchinski. 1997. The Effects of Spinning Conditions on Asymmetric 6FDA/6FDAM Polyimide Hollow Fibers for Air Separation. J. Appl. Polym. Sci. 65(8): 15551569 .

[30] Lin, WH and TS. Chung. 2000. The Physical Ageing Phenomenon of 6FDA-durene Polyimide Hollow Fibre Membranes. J. Polym. Sci. B: Polym Physics. 38: 765-775.

[31] Carruthers, S.B., G.L. Ramos, and W.J. Koros. 2003. Morphology of Integral-skin Layers in Hollow-fiber Gas-separation Membranes. J. Appl. Polym. Sci. 90: 399-411. 
32] Kazama, S. and M. Sakashita. 2005. Gas Separation Properties and Morphology of Asymmetric Hollow Fiber Membranes Made from Cardo Polyamide. J. Membr. Sci. 243: 59-68.

[33] Barsena, J.N., G.C. Kapantaidakis, N.F.A. van der Vegt, G.H. Koops, and M. Wessling. 2003 Preparation and Characterization of Highly Selective Dense and Hollow Fiber Asymmetric Membranes Based on BTDA-TDI/MDI co-polyimide. J. Membr. Sci. 216: 195-205.

[34] Madden, W.C., D. Punsalan, and W.J. Koros. 2005. Drifts in Penetrant Partial Molar Volumes in Glassy Polymers Due to Physical Aging. Polymer. 46: 5433-5436.

[35] Vieth, W.R. Diffusion in, and through polymers, 1990. New York: Hanser.

[36] M. Yoshino, M., S. Nakamura, H. Kita, K. Okamoto, N. Tanihara, and Y. Nusuki. 2003. Olefin/ paraffin Separation Performance of Asymmetric Hollow Fiber Membrane of 6FDA/BPDADDBT Copolyimide. J. Membr. Sci. 212: 13-27.

[37] Koros, W.J., and D.G. Woods. 2001. Elevated Temperature Application of Polymer Hollowfiber Membranes. J. Membr. Sci. 181: 157-166.

[38] Wang, D., K. Li, and W.K. Teo. 2002. Preparation of Asymmetric Polyetherimide Hollow Fibre Membrane with High Gas Selectivities. J. Membr. Sci. 208: 419-436.

[39] Wang, D., W.K. Teo, and K. Li. 2002. Permeation of $\mathrm{H}_{2}, \mathrm{~N}_{2}, \mathrm{CH}_{4}, \mathrm{C}_{2} \mathrm{H} 6$, and $\mathrm{C}_{3} \mathrm{H}_{8}$ Through Asymmetric Polyetherimide Hollow-fiber Membranes. J. Appl. Polym. Sci. 86: 698-702.

[40] Kapantaidakis, G.C., G.H. Koops, and M. Wessling. 2002. Effect of Spinning Conditions on the Structure and the Gas Permeation Properties of High Flux Polyethersulfone-polyimide Blend Hollow Fibers. Desalination. 144: 121-125.

[41] Kapantaidakis, G.C., and G.H. Koops. 2002. High Flux Polyethersulfone-polyimide Blend Hollow Fiber Membranes for Gas Separation. J. Membr. Sci. 204: 153-171.

[42] Kapantaidakis, G.C., G.H. Koops, and M. Wessling. 2002. Preparation and Characterization of Gas Separation Hollow Fiber Membranes Based on Polyethersulfone-polyimide Miscible Blends. Desalination 145: 353-357.

[43] Khulbe, K.C., C. Feng, T. Matsuura, G.C. Kapantaidakis, M. Wessling, and G.H. Koops. 2003 $\mathrm{CO}_{2}$ Plasticization of Polyethersulfone/polyimide Gas-separation Membranes. J. Membr. Sci. 226: 63-73.

[44] Wang, D., K. Li, and W.K. Teo. 1998. Preparation and Characterization of Polyetherimide Asymmetric Hollow Fiber Membranes for Gas Separation. J. Membr. Sci. 138: 193-201.

[45] Qin, J.J., and T.S. Chung. 2005. 229 ACS Meeting, San Diego, CA March13-17 (Abstract No. 62)

[46] Meng, B., N. Yang, X.Y. Tan, and B.Y. Zhang. 2005. Preparation of Polyvinylidene Fluoride/ Polyvinyl Dimethylsiloxane Composite Hollow Fiber Membranes and Their Separation Properties. Chinese J. Polym. Sci. 23: 75-82.

[47] Yeow, M.L., Y. Liu, and K. Li. 2005. Preparation of Porous PVDF Hollow Fibre Membrane via a Phase Inversion Method Using Lithium Perchlorate (LiClO4) as an Additive. J. Membr. Sci. 258: $16-22$.

[48] Berghmans, S., J. Mewis, H. Berghmans, and H. Meijer. 1995. Phase Behaviour and Structure Formation in Solutions of poly (2,6-dimethyl-1,4-phenylene ether). Polymer. 36: 3085-3091.

[49] Tsai, H.A., C.Y. Kuo, J.H. Lin, D.M. Wang, A. Deratani, C. Pochat-Bohatier, K.R. Lee, and J.Y. Lai. 2006. Morphology Control of Polysulfone Hollow Fiber Membranes via Water Vapor Induced Phase Separation. J. Membr. Sci. 278: 390-400.

[50] Tsai, H.A., Y.S. Ciou, C.C. Hu, K.R. Lee, D.G. Yu, and J.Y. Lai. 2005. Heat-treatment Effect on the Morphology and Pervaporation Performances of Asymmetric PAN Hollow Fiber Membranes. J. Membr. Sci. 255: 33-47.

[51] Shen, J., L. Wu, J. Qiu, and C. Gao. 2007. Pervaporation Separation of Water/isopropano Mixtures Through Crosslinked Carboxymethyl Chitosan/polysulfone Hollow-fiber Composite Membranes. J. Appl. Polym. Sci. 103: 1959-1965.
[52] Wu, B., X. Tan, W.K. Teo, and K. Li. 2005. Removal of Benzene/Toluene from Water by Vacuum Membrane Distillation in a PVDF Hollow Fiber Membrane Module. Sep. Sci. Technol. 40 2679-2695.

[53] Wu, B., X. Tan, K. Li, and W.K. Teo. 2006. Removal of 1,1,1-trichloroethane from Water Using a Polyvinylidene Fluoride Hollow Fiber Membrane Module: Vacuum Membrane Distillation Operation. Sep. Purif. Technol. 52: 301-309.

[54] Keller, A.A., and B.G. Bierwagen. 2001. Hydrophobic Hollow Fiber Membranes for Treating MTBE-Contaminated Water. Environ. Sci. Technol. 35: 1875-1879.

[55] Yamaguchi, T., T. Suzuki, T. Kai, and S. Nakao. 2001. Hollow-fiber-type Pore-filling Membranes Made by Plasma-graft Polymerization for the Removal of Chlorinated Organics from Water J. Membr. Sci. 194: 217-228.

[56] Chung, I.J., K.R. Lee, and S.T. Hwang. 1995. Separation of CFC-12 from Air by Polyimide Hollow-fiber Membrane Module. J. Membr. Sci. 105: 177-185.

[57] Yeow, M.L., R.W. Field, K. Li, and W.K. Teo. 2002. Preparation of Divinyl-PDMS/PVDF Composite Hollow Fibre Membranes for BTX Removal. J. Membr. Sci. 203: 137-143.

[58] Zhen, H., S.M.J. Jang, W.K. Teo, and K. Li. 2006. Modified Silicone-PVDF Composite Hollowfiber Membrane Preparation and its Application in VOC Separation. J. Appl. Polym. Sci. 99 2497-2503.

[59] Majumdar, S., D. Bhaumik, K.K. Sirkar. 2003. Performance of Commercial-size Plasmapolymerized PDMS-coated Hollow Fiber Modules in Removing VOCs from $\mathrm{N}_{2} /$ air J. Membr. Sci. 214: 323-330.

[60] Bhaumic, D., S. Majumdar, Q. Fan, and K.K. Sirkar. 2004. Hollow Fiber Membrane Degassing in Ultrapure Water and Microbiocontamination. J. Membr. Sci. 235: 31-41.

[61] Kosaraju, P., A.S. Kovvali, A. Korikov, and K.K. Sirkar. 2005. Hollow Fiber Membrane Contactor Based $\mathrm{CO}_{2}$ Absorption Stripping Using Novel Solvents and membranes. Ind. Eng. Chem. Res. 44: $1250-1258$.

[62] Wang, J., Y. Xu, Z. Xu, and H. Xu. 2001. A Study on the PP Hollow Fiber Membrane Contactor and its Performance for Removing Ammonia from Wastewater or Mixed Gas: II. Ammonia Removal from Mixed Gas. Water Supply. 1: 195-198.

[63] Li, K. 2002. Designing Asymmetric PVDF Hollow Fibres for Soluble Gas Removal. Chem Eng. Technol. 25: 203-206.

[64] Tan, X., S.P. Tan, W.K. Teo, and K. Li. 2006. Polyvinylidene Fluoride (PVDF) Hollow Fibre Membranes for Ammonia Removal from Water. J. Membr. Sci. 271: 59-68.

[65] Idris, A., A.F. Ismail, S.J. Shilton, R. Roslina, and M. Musa. 2002. The Deduction of Fine Structural Details of Reverse Osmosis Hollow Fiber Membranes Using Surface Force-pore Flow Model. Sep. Purif. Technol. 29: 217-227.

[66] Qin, J.J., Y. Li, and H. Lee. 2003. 5th IMSTEC'2003 Sydney. Australia, Nov. 10-14.

[67] Soltys, P.J., N.J. Ofsthun, and A.L. Zydney. 1996. Asymmetric Solute Transport and Solvent Flux in Dual-skinned Hollow Fiber Membranes. J. Membr. Sci. 118: 199-212.

[68] Khayet, M., D.E. Suk, R.M. Narbaitz, J.P. Santree, and T. Matsuura. 2003. Study on Surface Modification by Surface-modifying Macromolecules and its Applications in Membraneseparation Processes. J. Appl. Polym. Sci. 89: 2902.

[69] Ishihara, K., T. Hasegawa, J. Watanabe, and Y. Iwasaki. 2002. Artificial Organs 26: 1014-1019.

[70] Tan, X., N.N. Kyaw, W.K. Teo, and K. Li. 2006. Decolorization of Dye-containing Aqueous Solutions by the Polyelectrolyte-enhanced Ultrafiltration (PEUF) Process Using a Hollow Fiber Membrane Module. Sep. Purif. Technol. 52: 110-116.

[71] Chung, T.S., J.J. Qin, A. Huan, and K.C. Toh. 2001. Visualization of the Effect of Die Shear Rate on the Outer Surface Morphology of Ultrafiltration Membranes by AFM. J. Membr. Sci. 196: 251-256. 
[72] Wang, K.Y., T. Matsuura, T.S. Chung, and W.F. Guo. 2004. The Effects of Flow Angle and Shear Rate Within the Spinneret on the Separation Performance of poly(ethersulfone) (PES) Ultrafiltration Hollow Fiber Membranes. J. Membr. Sci. 240: 67-69.

[73] Khare, V.P., A.R. Greenberg, and W.B. Krantz. 2005. Vapor-induced Phase Separation-effect of the Humid Air Exposure Step on Membrane Morphology: Part I. Insights from Mathematical Modeling. J. Membr. Sci. 258: 140-156.

[74] Ochoa, N.A., P. Pradanos, L. Palacio, C. Pagliero, J. Marchese, and A. Hernandez. 2001. Pore Size Distributions Based on AFM Imaging and Retention of Multidisperse Polymer Solutes: Characterisation of Polyethersulfone UF Membranes with Dopes Containing Different PVP. J. Membr. Sci. 187: 227-237.

[75] Ameri, A., M. Gholami, N. Nasseri, and T. Matsuura. 2004. Modification of Polyether Sulfone (PES) Hollow Fiber Membranes Characteristics for More Efficient Water Treatment Process. Iranian J. Publ. Health 33: 49-55.

[76] Khulbe, K.C., C.Y. Feng, F. Hamad, T. Matsuura, and M. Khayet. 2004. Structural and Performance Study of Micro Porous Polyetherimide Hollow Fiber Membranes Prepared at Different Air-gap. J. Membr. Sci. 245: 191-198.

[77] Feng, C.Y., K.C. Khulbe, G. Chowdhury, T. Matsuura, and V.C. Sapkal. 2001. Structural and Performance Study of Microporous Polyetherimide Hollow Fiber Membranes Made by Solventspinning Method. J. Membr. Sci. 189: 193-203.

[78] Xu, Z.K., L.Q. Shen, Q. Yang, F. Liu, S.Y. Wang, and Y.Y. Xu. 2003. Ultrafiltration Hollow Fiber Membranes from poly (ether imide): Preparation, Morphologies and Properties. J. Membr. Sci. 223: 105-118.

[79] Tasseli, F., J.C. Jansen, F. Sidari, and E. Drioli. 2005. Morphology and Transport Property Control of Modified poly(ether ether ketone) (PEEKWC) Hollow Fiber Membranes Prepared from PEEKWC/PVP Blends: Influence of the Relative Humidity in the Air Gap. J. Membr. Sci. 235: $13-22$.

[80] Tasselli, F., J.C. Jansen, and E. Drioli. 2003. PEEKWC Ultrafiltration Hollow-fiber Membranes: Preparation, Morphology, and Transport Properties. J. Appl. Polym. Sci. 91: 841-853.

[81] Khayet, M., C.Y. Feng, K.C. Khulbe, and T. Matsuura. 2002. Preparation and Characterization of Polyvinylidene Fluoride Hollow Fiber Membranes for Ultrafiltration Polymer. 43: 3879-3890.

[82] Giorno, L., N. Li, and E. Drioli. 2003. Preparation of Oil-in-water Emulsions Using Polyamide 10 kDa Hollow Fiber Membrane. J. Membr. Sci. 217: 173-180.

[83] Korikov, A.P., P.B. Kosaraju, and K.K. Sirkar. 2006. 279: 588-600

[84] Yang, Z., P. Li; L. Xie, Z. Wang, and W. Shi-Chang. 2006. Preparation of iPP Hollow-fiber Microporous Membranes via Thermally Induced Phase Separation with Co-solvents of DBP and DOP. Desalination. 192: 168-181.

[85] Matsuyama, H., K. Hayashi, T. Maki, M. Teramoto, and N. Kubota. 2004. Effect of Polymer Density on Polyethylene Hollow Fiber Membrane Formation via Thermally Induced Phase Separation. J. Appl. Polym. Sci. 93: 471-474.

[86] Fu, X., H. Matsuyama, M. Teramoto, and $\mathrm{H}$. Nagai 2006. Preparation of Polymer Blend Hollow Fiber Membrane via Thermally Induced Phase Separation. Sep. Purif. Technol. 52: 363-371.

[87] Faria, L.F.F., M.D. Luccio, R. Nobrega, and C.P. Borges. 2002. Including Model Uncertainty in the Model Predictive Control with Output Feedback. Braz. J. Chem. Eng. 19: 1-11.

[88] Luque, S., H. Mallubhotia, G. Gehlert, R. Kuriyel, S. Dzengeleski, S. Pearl, and G. Belfort. 2000. A New Coiled Hollow-fiber Module Design for Enhanced Microfiltration Performance in Biotechnology. Biotech. Bioeng. 65: 247-257.

[89] Kobayashi, T. and Y. Hosaka. 2003. Ultrasoundly Enhanced Membrane Treatment for Hollow Fiber Microfiltration in Controlled Sonic Field. Jpn. J. Appl. Phys. 42: 2954-2955.
[90] Broek, A.P., H.A. Teunis, D. Bargeman, E.D. Sprengers, and C.A. Smolders. 1992 Characterization of Hollow Fiber Hemodialysis Membranes: Pore Size Distribution and Performance. J. Membr. Sci. 73: 143-152.

[91] Ye, S.H., J. Watanabe, M. Takai, Y. Iwasaki, and K. Ishihara. 2005. Design of Functional Hollow Fiber Membranes Modified with Phospholipids Polymers for Application Hemopurification System. Biomaterials. 26: 5032-41.

[92] Ye, S.H., J. Watanabe, and K. Ishihara. 2004. Cellulose Acetate Hollow Fiber Membranes Blended with Phospholipid Polymer and their Performance for Hemopurification. J. Biomater. Sci. Polym. Ed. 15(8): 981-1001.

[93] Hayama, M., F. Kohori, and K. Sakai. 2002. AFM Observation of Small Surface Pores of Hollowfiber Dialysis Membrane Using Highly Sharpened Probe. J. Membr. Sci. 197: 243-249.

[94] Rafat, M., D. De, K.C. Khulbe, T. Nguyen, and T. Matsuura. 2006. Surface Characterization of Hollow Fiber Membranes Used in Artificial Kidney I. Appl. Polym. Sci. 101: 4385-4400.

[95] Lee, S.H., J.J. Kim, S.S. Kim, and U.Y. Kim. 1993. Morphology and Performance of Polysulfone Hollow Fiber Membrane. J. Appl. Polym. Sci. 49: 539-548.

[96] Torto, N., M. Ohirogge, L. Gorton, J.M.V. Alstine, T. Laurell, G. Marko-Varga. 2004. In Situ poly (ethylene imine) Coating of Hollow Fiber Membranes Used for Microdialysis Sampling. Pure Appl. Chem. 76: 879-888.

[97] Barzin, J., C. Feng, K.C. Khulbe, T. Matsuura, S.S. Madaeni, and H. Mirzadeh. 2004 Characterization of Polyethersulfone Hemodialysis Membrane by Ultrafiltration and Atomic Force Microscopy. J. Membr. Sci. 237: 77-85.

[98] Ishikiriyama, K., A. Sakamoto, M. Todoki, T. Tayama, K. Tanaka, and T. Kobayashi. 1995. Pore Size Distribution Measurements of Polymer Hydrogel Membranes for Artificial Kidneys Using Differential Scanning Calorimetry. Thermochimica Acta. 267: 169-180.

[99] Sugaya, H. and Y. Sakai. 1998. Polymethylmethacrylate: From Polymer to Dialyzer. Contrib. Nephrol Basel Karger. 125: 1-8.

[100] Chung, T.S., Z.L. Xu, and W. Lin W.1999. Fundamental Understanding of the Effect of Airgap Distance on the Fabrication of Hollow Fiber Membranes. J. Appl. Polym. Sci. 72: 379395.

[101] Shih, C.H., C.C. Gryte, and L.P. Cheng. 2005. Modeling of the Wet Spinning Process for Hollow Fiber Membrane Formation. Proc. Applied Simulation, and Modelling. 469-042.

[102] Pereira, C.C., R. Nobrega, C.P. Borges. 2000. Braz. J. Chem. Eng. 17: 4-7.

[103] Khare, V.P., A.R. Greenberg, W.B. Krantz. 2005. Vapor-induced Phase Separation-Effect of the Humid Air Exposure Step on Membrane Morphology: Part I. Insights from Mathematical Modeling. J. Membr. Sci. 258: 140-156.

[104] Sasaki, J., K. Naruo. 1990. US Patent 4, 9333,081.

[105] Sasaki, J., A. Adachi, K. Naruo, Y. Shinagawa, and S. Ohtani. 1998. Fine Porous Membrane and Process for Producing the Same. US Patent 4,840,733.

[106] Wang, I. 2000. US Patent 5,869,164.

[107] Wang I. J.F. Ditter, and R. Morris. 1999. Microfiltration Membranes Having High Pore Density and Mixed Isotropic and Anisotropic Structure. US Patent 5,906,742.

[108] Wang I., R.A. Morris, and R.F. Zepf. 2000. Highly Asymmetric, Hydrophilic, Microfiltration Membranes Having Large Pore Diameters. US Patent 6, 045,899.

[109] Goma-Bilongo, T., A. Akbari, M.J. Clifton, and J.C. Remigy. 2006. Numerical Simulation of a uv Photografting Process for Hollow-fiber Membranes. J. Membr. Sci. 278: 308-317.

[110] Ye, X., L. Lv, X.S. Zhao, and K. Wang. 2006. Permeation Time Lag in Polymeric Hollow Fiber Membranes. J. Membr. Sci. 283: 425-429.

[111] Pan, C.Y 1986. Gas Separation by High-flux, Asymmetric Hollow-fiber Membrane. AIChE Journal. 32: 2020-2027. 
[112] Gabelman, A., S.T. Hwang. 1999. Hollow Fiber Membrane Contactors. J. Membr. Sci. 159: 61-106.

[113] Gabelman, A. and S.T. Hwang ST. 2006. A Theoretical Study of Dense Gas Extraction Using a Hollow Fiber Membrane Contactor. J. Supercritical Fluids. 37: 157-172.

[114] Gabelman, A., S.T. Hwang., and W.B. Krantz. 2005. Dense Gas Extraction Using a Hollow Fiber Membrane Contactor: Experimental Results versus Model Predictions. J. Membr. Sci. 257: $11-36$

[115] Mi, L. and S.T. Hwang. 1999. Correlation of Concentration Polarization and Hydrodynamic Parameters in Hollow Fiber Modules. J. Membr. Sci. 159: 143-165.

[116] Song, L., B. Li, K.K. Sirkar, and J.L. Gilron. 2007. Direct Contact Membrane Distillationbased Desalination: Novel Membranes, Devices, Larger-scale Studies, and a Model. Ind. Eng. Chem. Res. 46: 2307-232.

[117] Macheras, J.T., T.A. Bolan, and B. Bikson. 1999. Method and Apparatus for Spinning Hollow Fiber Membranes. US Patent 5,871,680.

[118] Puri, P.S. 1988. Process for Making Highly Permeable Coated Composite Hollow Fiber Membranes. US Patent 4,756,932.

[119] Macheras, J.T., B. Bikson, and J.K. Nelson. 1999. Method of Preparing Membranes from a Blends of Polymers. US Patent 5,891,572.

[120] Lee, M.S., and K.J. Lee. 2007. Nano Composite Hollow Fiber Membrane and Method of Manufacturing the Same. Patent WO 018393.

[121] Klotzer, R., B. Seibig, D. Paul, and K.V. Peinemann. 1999. Method of Producing Hollow Fiber Polymer Membranes. US Patent 5980795.

[122] Kakiuchi, T., K.S. Sekiguchi, T. Suehiro, Y. Matsumoto, M. Takai, N. Sugo, and H. Tsuruta 2003. Hollow Fiber Membrane Made of an Ethylene-vinyl Alcohol Polymer. US Patent 6514409.

[123] Cheng, K.S., R.B. Patel, and T.D. Gates. 2004. Microporous Hollow Fiber Membranes from Perfluorinated Thermoplastic Polymers. US Patent 6802972 B1

[124] Gao, Y., N. Guo, B. Gauvreau, M. Rajabian M, O. Skorobogata, E. Pone, O. Zabeida, L. Martinu, C. Dubois, and M. Skorobogatiy. 2006. Consecutive Solvent Evaporation and Corolling Techniques for Polymer Multilayer Hollow Fiber Preform Fabrication. IEEE 22462254.

[125] Qi, S. and M.L. Lee. 1998. Polypropylene Hollow Fibers Modified with PMMA for Capillary Electrophoresis. J. Microcolumn Sep. 10: 605-609.

[126] Guibal, E., T. Vincent, and S. Spinelli. 2005. Environmental Application of Chitosan-supported Catalysts: Catalytic Hollow Fibers for the Degradation of Phenolic Derivatives. Sep. Sci. Technol. 40: 633-657.

[127] Gao, H., Y. Xu, S. Liao, R. Liu, J. Liu, D. Li, D. Yu, Y. Zhao,, and Y. Fan. 1995. Catalytic Polymeric Hollow-fiber Reactors for the Selective Hydrogenation of Conjugated Dienes. J. Membr. Sci. 106: 213-219.

[128] Moeder, M., C. Martin, and G. Koeller. 2004. Degradation of Hydroxylated Compounds Using Laccase and Horseradish Peroxidase Immobilized on Microporous Polypropylene Hollow Fiber Membranes. J. Membr. Sci. 245: 183-190.

[129] Basheer, C., A. Jayaraman, M.K. Kee, C.S. Valiyaveetti, and H.K. Lee. 2005. Polymer-coated Hollow-fiber Microextraction of Estrogens in Water Samples with Analysis by Gas Chromatography-mass Spectrometry. J. Chromatogr. A. 1100: 137-43.

[130] Song, L., S.O. Christian, B. Li, D.M. Zarkass, and K.K. Sirkar. 2006. The 2006 Annual Meeting, Engineering Science, and Fundamentals, \#279.

[131] Liu, P.Z., A. Malik, M.C.J. Kuchar, W.P. Vorkink, and M.L. Lee. 2005. Polymeric Hollow Fibers for Capillary Electrophoresis. J. Microcolumn Sep. 5(3): 245-253.
[132] Büyüktuncel, E., S. Bektas, P Genc, and A. Denizli. 2001. Poly(vinylalcohol) Coated/Cibacron Blue F3GA-attached Polypropylene Hollow Fiber Membranes for Removal of Cadmium Ions from Aquatic Systems. Reactive, and Functional Polym. 47: 1-10.

[133] Sakai, M., and S. Matsunami. 2003. The Structure and Characteristics of Polypropylene Hollow Fiber Membrane Plasma Separator. Therapeutic Apheresis, and Dialysis. 7: 69-72

[134] Kusumocahyo, S.P., T. Kanamori, T. Iwatsubo. K. Sumaru. T. Shinbo, H. Matsuyama, and M Teramoto. 2006. Modification of Preparation Method for Polymer Inclusion Membrane (PIM) to Produce Hollow fiber PIM. J. Appl. Polym. Sci. 102: 4372-4377.

[135] Fujii, Y., H. Iwatani, and S. Kigoshi. 1992. Morphological Structures of the Membranes Prepared from Polymer Solutions. Polym. J. 24: 737-755.

[136] Chung, T.S. and X. Hu. 1998. Effect of Air-gap Distance on the Morphology and Thermal Properties of Polyethersulfone Hollow Fibers. I. Appl. Polym. Sci. 66: 1067-1077.

[137] Qin, J.J. 2005. 229 ACS National Meeting. San Diego, CA. March 13-17, \# 62.

[138] Weigel, T., E. Schulz, W. Makschin, W. Albrecht, P. Klug, and. V. GrQbe 1990. Acta Polymerica 39: 174-177.

139] Saufi, S.M., and A.F. Ismail. 2002. Development and Characterization of Polyacrylonitrile (PAN) Based Carbon Hollow Fiber Membrane. Songklanakarin J. Sci. Technol. 24(suppl.): 843-854.

[140] Xiuli, Y., C. Hongbin, W. Xiu, and Y. Yongxin. 1998. Morphology and Properties of Hollowfiber Membrane Made by PAN Mixing with Small Amount of PVDF. J. Membr. Sci. 146:179184

141] Mei, L., D. Zhang, and Q. Wang. 2002. Morphology Structure Study of Polypropylene Hollow Fiber Membrane Made by the Blend-spinning and Cold-stretching Method. J. Appl. Polym. Sci. 84: 1390-1394

[142] Hong J.M. S.R. Ha . H C. Park, Y. K. Kang and K.H. Ahn. 1998. Method for Preparing Porous Membranes Utilizing Water or Organic Vapor Adsorption. US Patent 5,708,040.

[143] Kong J and K. Li. 2001. An Improved Gas Permeation Method for Characterising and Predicting the Performance of Microporous Asymmetric Hollow Fibre Membranes used in Gas Absorption. J. Membr. Sci. 182: 271-281.

[144] Li, X. and C. Xiao. 2005. Structure and Properties of Composite Polyurethane Hollow Fiber Membranes. Chinese I. Polym. 23: 203-210.

[145] Li, S.G. G.H. Koops, M.H.V. Mulder, T. van den Boomgaard, and C.A. Smolders. 1994. Wet Spinning of Integrally Skinned Hollow Fiber Membranes by a Modified Dual-bath Coagulation Method Using a Triple Orifice Spinneret. J. Membr. Sci. 94: 329.

[146] Wienk, I.M., H.A. Teunwas, T. van den Boomgaard, and C.A. Smolders. 1993. A New Spinning Technique for Hollow Fiber Ultrafiltration Membranes. J. Membr. Sci. 78: 93.

147] Zhen, H., S.M.J. Jang, W.K. Teo, and K. Li. 2006. Modified Silicone-PVDF Composite Hollowfiber Membrane Preparation and its Application in VOC Separation. J. Appl. Polym. Sci. 99: 2497-2503.

[148] Henne, W., G. Dunweg, W. Schmitz, R. Pohle, and F. Lawitzki. Method of Producing Dialyzing Membrane. 1979. US Patent 4,164,437.

[149] Kusuki, Y T Yoshinaga, and H. Shimazaki 1989. Pressure-resistant Bilayer Polyimide Hollowfiber Membrane Preparation. Japanese Patent 01099616.

[150] Yoshinaga, T., H. Shimazaki, and Y. Kusuki. 1990. Polyimide Bilayer Hollow Membranes and Their Manufacture. Japanese Patent 02169019

[151] Yoshinaga, T. H. Shimazaki, and Y. Kusuki. 1990. Polyimide Bilayer Hollow-Fiber Gas Separation Membranes and Their Manufacture. Japanese Patent 02251232.

[152] Ekiner, O.M., R.A. Hayes, and P. Manos.1992. Novel Multicomponent Fluid Separation Membranes. US patent 5085676 
[153] Suzuki, H., H. Tanaka, K. Kita, H. Okamoto, H. Hoshino, T. Yoshinaga, and Y. Kusuki. 1998. Preparation of Composite Hollow Fiber Membranes of Poly (ethylene oxide)-containing Polyimide and their $\mathrm{CO}_{2} / \mathrm{N}_{2}$ Separation Properties. J. Membr. Sci. 146: 31.

[154] Li, D.F., T.S. Chung, R. Wang, and Y. Liu. 2002. Fabrication of Fluoropolyimide/ polyethersulfone (PES) Dual-Layer Asymmetric Hollow Fiber Membranes for Gas Separation. J. Membr. Sci. 198: 211-223.

[155] Li, D., T.S. Chung, and R. Wang. 2004. Morphological Aspects and Structure Control of Dual-Layer Asymmetric Hollow Fiber Membranes Formed by a Simultaneous Co-Extrusion Approach. J. Membr. Sci. 243: 155-175.

[156] Li, Y., C. Cao, T.S. Chung, and K.P. Pramoda. 2004. Fabrication of Dual-Layer Polyethersulfone (PES) Hollow Fiber Membranes with an Ultrathin Dense-Selective Layer for Gas Separation. J. Membr. Sci. 245: 53-60

[157] Pereira, C.C., R. Nobrega, K.V. Peinemann, and C.P. Borges. 2003. Hollow Fiber Membranes obtained by Simultaneous Spinning of Two Polymer Solutions: A Morphological Study. J. Membr. Sci. 226: 35-50.

[158] Yang, S., W.K. Teo, and K. Li. 2001. Formation of Annular Hollow Fibres for Immobilization of Yeast in Annular Passages. J. Membr. Sci. 184: 107-115.

[159] He, T., H.V. Mulder, and M. Wessling. 2003. Preparation of Porous Hollow Fiber Membranes with a Triple-Orifice Spinneret. J. Appl. Polym. Sci. 87: 2151-2157.

[160] Albrecht, W., K. Kneifel, Th. Weigel, R. Hilke, R. Just, M. Schossig, K. Ebert, and A. Lendlein. 2005. Preparation of Highly Asymmetric Hollow Fiber Membranes from Poly (Ether Imide) by a Modified Dry-Wet Phase Inversion Technique Using a Triple Spinneret. J. Membr. Sci. 262: 69-80.

[161] Box, G.E.P., W.G. Hunter, and J.S. Hunter. 1978. in Statistics for Experiments: An Introduction to Design, Data Analysis, and Model Building, New York: Jon Wiley \& Sons.

[162] Wood, M. 2002. Ph.D. Thesis, University Ottawa, Ottawa, Canada.

[163] Idris, A., A.F. Ismail, M.Y. Noordin, and S.J. Shilton. 2002. Optimization of Cellulose Acetate Hollow Fiber Reverse Osmosis Membrane Production using Taguchi Method. J. Membr. Sci. 205: 223-237.

[164] Pesek, S.C. and W.J. Koros. 1994. Aqueous Quenched Asymmetric Polysulfone Hollow Fibers Prepared by Dry/Wet Phase Separation. J. Membr. Sci. 88:1.

[165] Kesting, R.E. and A.K. Fritzsche. 1993. in Polymeric Gas Separation Membranes. New York: John Wiley \& Sons. p 264, and 265.

[166] Fujii, Y., H. Iwatani, and S. Kigoshi. 1992. Morphological Structures of the Membranes Prepared from Polymer Solutions. Polym. J. 24: 737-755.

[167] Wienk, I.M., Th. Vn den Boomgaard, and C.A. Smolders. 1994. The Formation of Nodular Structures in the Top Layer of Ultrafiltration Membranes. J. Appl. Polym. Sci. 53: 1011.

[168] Khulbe, K.C., C. Feng, T. Matsuura, and M. Khayet. 2006. AFM Images of the Cross-Section of Polyetherimide Hollow Fibers. Desalination. 201: 130-137. 